Cochrane Database of Systematic Reviews

\title{
Oral vasodilators for primary Raynaud's phenomenon (Review)
}

Stewart M, Morling JR

Stewart M, Morling JR.

Oral vasodilators for primary Raynaud's phenomenon.

Cochrane Database of Systematic Reviews 2012, Issue 7. Art. No.: CD006687.

DOI: 10.1002/14651858.CD006687.pub3.

www.cochranelibrary.com 
TABLE OF CONTENTS

HEADER 1

ABSTRACT

PLAIN LANGUAGE SUMMARY

BACKGROUND

OBJECTIVES

METHODS

RESULTS

DISCUSSION

AUTHORS' CONCLUSIONS

ACKNOWLEDGEMENTS

REFERENCES

CHARACTERISTICS OF STUDIES

DATA AND ANALYSES

Analysis 1.1. Comparison 1 ACE inhibitor versus placebo, Outcome 1 Frequency of attacks per week..

Analysis 2.1. Comparison 2 Captopril versus placebo, Outcome 1 Frequency of attacks per week.

Analysis 2.2. Comparison 2 Captopril versus placebo, Outcome 2 Duration per attack (minutes).

Analysis 3.1. Comparison 3 Enalapril versus placebo, Outcome 1 Subjective assessment of improvement $(10 \mathrm{~cm}$ Visual Analogue

Scale).

Analysis 4.1. Comparison 4 Buflomedil versus placebo, Outcome 1 Frequency of attacks per week.

Analysis 4.2. Comparison 4 Buflomedil versus placebo, Outcome 2 Severity (1:mild, 2:moderate, 3:severe).

Analysis 5.1. Comparison 5 Beraprost versus placebo, Outcome 1 Frequency of attacks per week.

Analysis 5.2. Comparison 5 Beraprost versus placebo, Outcome 2 Severity of attacks (1-4 scale).

Analysis 5.3. Comparison 5 Beraprost versus placebo, Outcome 3 Disability (100 mm Visual Analogue Scale).

Analysis 5.4. Comparison 5 Beraprost versus placebo, Outcome 4 Adverse events.

Analysis 6.1. Comparison 6 Dazoxiben versus placebo, Outcome 1 Frequency of attacks per week.

Analysis 7.1. Comparison 7 Ketanserin versus placebo, Outcome 1 Frequency of attacks per week.

Analysis 7.2. Comparison 7 Ketanserin versus placebo, Outcome 2 Duration of attacks per day (minutes).

Analysis 7.3. Comparison 7 Ketanserin versus placebo, Outcome 3 Severity score (frequency of attacks/day X duration of attacks).

Analysis 7.4. Comparison 7 Ketanserin versus placebo, Outcome 4 Adverse events.

Analysis 8.1. Comparison 8 Moxisylyte (Thymoxamine) versus placebo, Outcome 1 Adverse events.

Analysis 9.1. Comparison 9 Any drug versus placebo, Outcome 1 Differences in mean frequencies of attacks per week. ADDITIONAL TABLES

APPENDICES

WHAT'S NEW

HISTORY

CONTRIBUTIONS OF AUTHORS

DECLARATIONS OF INTEREST

SOURCES OF SUPPORT

INDEX TERMS 
[Intervention Review]

\section{Oral vasodilators for primary Raynaud's phenomenon}

Marlene Stewart ${ }^{1}$, Joanne R Morling 1

${ }^{1}$ Centre for Population Health Sciences, University of Edinburgh, Edinburgh, UK

Contact address: Marlene Stewart, Centre for Population Health Sciences, University of Edinburgh, Teviot Place, Edinburgh, EH8 9AG, UK. Marlene.Stewart@ed.ac.uk.

Editorial group: Cochrane Vascular Group.

Publication status and date: New search for studies and content updated (no change to conclusions), published in Issue 7, 2012.

Citation: Stewart M, Morling JR. Oral vasodilators for primary Raynaud's phenomenon. Cochrane Database of Systematic Reviews 2012 , Issue 7. Art. No.: CD006687. DOI: 10.1002/14651858.CD006687.pub3.

Copyright @ 2012 The Cochrane Collaboration. Published by John Wiley \& Sons, Ltd.

\section{A B S T R A C T}

\section{Background}

Many different drugs have been suggested for the symptomatic treatment of primary Raynaud's phenomenon. Apart from calcium channel blockers, which are considered the drugs of choice, the evidence of the effects of alternative pharmacological treatments is limited. This is an update of a review first published in 2008.

\section{Objectives}

To assess the effects of various drugs with vasodilator actions on primary Raynaud's phenomenon.

\section{Search methods}

For this update the Cochrane Peripheral Vascular Diseases Group Trials Search Co-ordinator searched the Specialised Register (last searched 14 May 2012), CENTRAL (Issue 4, 2012) and clinical trials databases. We contacted one pharmaceutical company and one trial author for additional information. In addition, the reference lists of relevant studies were searched for additional citations. There were no language restrictions.

\section{Selection criteria}

Randomised controlled trials evaluating the effects of oral formulations of any drug with vasodilator effects on subjective symptoms in primary Raynaud's phenomenon. Treatment with, or comparison with, calcium channel blockers was not assessed in this review.

\section{Data collection and analysis}

Two members of the review team independently assessed the trials for inclusion and their quality and extracted the data. Data extraction included adverse events. We contacted trial authors for missing data.

\section{Main results}

Eight studies involving 290 participants were included. Two trials examined the effects of captopril, the rest were single trials on single drugs. All comparisons were with placebo. The methodological quality of most trials was poor.

Enalapril was associated with a small increase in the frequency of attacks per week (difference in means $0.8 ; 95 \% \mathrm{Cl} 0.43$ to 1.17 ). The difference between the intervention groups on a subjective improvement score was non-significant.

There was a significant effect of buflomedil on the frequency of attacks per week (weighted mean difference (WMD) $-8.8 ; 95 \% \mathrm{Cl}-17.55$ to -0.09), but there was no evidence of effect on the severity score.

The proportion with fewer attacks was significantly higher on moxisylyte than on placebo (relative risk (RR) $4.33 ; 95 \% \mathrm{Cl} 1.36$ to 13.81 ). For captopril, beraprost, dazoxiben and ketanserin there was no evidence of an effect on the frequency, severity or duration of attacks. Beraprost and moxisylyte gave significantly more adverse effects than placebo. 


\section{Authors' conclusions}

Poor methodological quality, small sample sizes and the limited data available resulted in low precision of the statistical results and limited value of the overall results. The overall results show that there is no evidence for an effect of vasodilator drugs on primary Raynaud's phenomenon.

\section{PLAIN LANGUAGE SUMMARY}

\section{Oral vasodilator drugs to reduce the symptoms of primary Raynaud's phenomenon}

Raynaud's phenomenon is caused by short term constriction of the small arteries in the extremities, usually the fingers. For a few minutes, usually, the fingertips go white and feel numb or tingle and prickle. Then the blood flow returns and they become warm and red, which can also be painful. For some people the toes, ears, nose, tongue or nipples are affected. Cold or emotional stress can trigger the attacks. Keeping warm, stopping smoking and avoiding using tools that vibrate can prevent attacks but sometimes drug therapy is needed. Calcium channel blockers such as nifedipine are the drugs of choice but can have unwanted side effects.

The review looked at the effectiveness of other drugs that can be taken by mouth. These were drugs that increase blood flow (vasodilators). The evidence from randomised controlled trials is limited. The review authors identified eight controlled studies. These were published between 1980 and 1996 and involved a total of 290 participants randomly assigned to the vasodilator drug or placebo. The length of treatment varied from two weeks to six months. Only two trials looked at the same drug, the angiotensin converting enzyme (ACE) inhibitor captopril so most of the findings were from single trials. Taking enalapril resulted in a small increase in the frequency of attacks in a week. Buflomedil reduced the frequency of attacks but without a clear effect on their severity. Moxisylyte (thymoxamine) also reduced attacks but both beraprost and moxisylyte produced more adverse effects than with placebo. For captopril, beraprost, dazoxiben and ketanserin there was no evidence of an effect on the frequency, severity or duration of attacks.

The methodological quality of most trials was poor and they were small. The outcomes were subjective and were reported on scales that were not well described or validated. This makes the clinical importance of the results difficult to assess, especially if the placebo response is high. 


\section{B A C K G R O U N D}

Raynaud's phenomenon was first described by Maurice Raynaud in 1862 (Ho 1998). It is a common disorder characterised by episodes of vasospasm (constriction) of the small arteries in the fingers as a response to exposure to cold, resulting in the classical well-demarcated whitening of one or more of the finger tips, sometimes followed by cyanosis. There may be pain and an abnormal sensation such as numbness or prickling sensation (paraesthesia). This is followed by a reactive increase in the blood flow (hyperaemia) to the finger upon reperfusion (Ho 1998). Fingers are most often affected, but in more severe cases the toes, ears, nose, tongue or nipples may be involved (Prodigy 2006).

In this review, the term primary Raynaud's phenomenon has been used for what is also called Raynaud's disease or idiopathic Raynaud's phenomenon. The term secondary Raynaud's phenomenon has been used for what is also called Raynaud's syndrome. Primary and secondary Raynaud's phenomenon are defined according to the absence or presence of underlying disease. There is a wide range of causes of secondary Raynaud's phenomenon. The most frequent and well known are connective tissue diseases, most often systemic sclerosis (Block 2001). Raynaud's phenomenon may be a side effect of some drugs; well known are beta blockers, ergotamines, interferon alpha, cyclosporine, and some antineoplastic chemotherapeutic agents. Among other causes are hypothyroidism, carpal tunnel syndrome, neoplasms including paraneoplastic syndrome, thoracic outlet syndrome and hand-arm vibration syndrome caused by occupational exposure to mechanical vibration (Prodigy 2006). Raynaud's phenomenon may be associated with other vasospastic disorders such as Prinzmetal's (variant) angina or migraine (Block 2001).

Suggested criteria for diagnosis of primary Raynaud's phenomenon include vasospastic attacks precipitated by cold or emotional stress, symmetric attacks involving both hands, absence of tissue necrosis, ulceration or gangrene, no history or physical findings suggesting secondary cause, normal nailfold capillaries, normal erythrocyte sedimentation rate and negative serologic findings, particularly anti-nuclear antibodies (Prodigy 2006; Wigley 2002).

A study in England found a prevalence of Raynaud's phenomenon of $11 \%$ to $16 \%$ in men and $19 \%$ to $21 \%$ in women (Silman 1990). Studies in warmer climates have found a prevalence of $3 \%$ to $4 \%$ (Wigley 2002). Most people with Raynaud's have developed symptoms before the age of 40 (Pope 2006). In the subset with more severe symptoms seen in a specialist setting, $80 \%$ to $90 \%$ have primary Raynaud's phenomenon (Hirschl 2006). The transition rate from primary to secondary Raynaud's phenomenon can be up to $1 \%$ to $2 \%$ per year for people monitored in a specialist setting, but the symptoms may also disappear (Spencer-Green 1998).

For most people primary Raynaud's phenomenon is a well known condition. It is at most a nuisance and is rarely mentioned even to the general practitioner (Silman 1990). Attacks usually last for a few minutes, but may last for hours. Rarely, superficial ulcers develop in patients with primary Raynaud's phenomenon. Patients with secondary Raynaud's phenomenon, especially associated with autoimmune diseases, may develop trophic changes (abnormalities of the skin or subcutaneous tissues), painful ulcers and gangrene (Block 2001). The symptomatic treatment of the two groups is the same. However, the progressive tissue damage seen in scleroderma-associated Raynaud's phenomenon may be the reason why many treatments are less effective in secondary Raynaud's phenomenon (Block 2001). Most patients can control their symptoms by conservative measures such as avoiding exposure to cold and using protective clothing. Smoking and other factors that may cause symptoms, including drugs and the use of vibratory tools, should be avoided. However, some people are more severely affected, with higher frequency and duration of attacks, often with seasonal variations. If symptoms do not respond adequately to conservative measures, nifedipine or an alternative calcium channel blocker is recommended as firstline treatment (Pope 2006; Prodigy 2006). Treatment with calcium channel blockers will be addressed in another Cochrane systematic review, and is not discussed in this review (Herrick 2008).

Calcium channel blockers may give unwanted side effects, and a range of other drugs have been suggested as alternatives because of their vasodilator action (widening of the blood vessels) and the experience with their use for other cardiovascular disorders (Block 2001; Pope 2006; Prodigy 2006; Wigley 2002). However, these reviews report limited evidence of the effects of these drugs on primary Raynaud's phenomenon. Among the various drugs, only a few are licensed for the treatment of Raynaud's phenomenon (BNF53; Medicines.org.uk). Others are licensed for peripheral vascular diseases. For a detailed list of drugs with vasodilator effects see additional Table 1. Antithrombotic treatments have been used for severe disease, especially secondary Raynaud's phenomenon (Block 2001). Intravenous treatment with prostacyclin analogues or cervical or digital sympathectomy are alternatives for patients with severe ischaemia of the fingers unresponsive to any other medical treatment. Digital or phalangeal amputations may be the final outcome (Wigley 2002). These complications are very rare in primary Raynaud's phenomenon.

Vascular tone is normally regulated by a complex interaction between smooth muscle, endothelium and innervation of the vessels. The primary defect in Raynaud's phenomenon is probably related to abnormal autoregulation of the small blood vessels (microvasculature). This might involve a combination of excessive release of vasoconstrictive mediators, exaggerated vasoconstrictive responses and blunted vasodilatory responses (Block 2001). However, the underlying process is still poorly understood (Pope 2006). Vasoconstriction in peripheral vessels is mediated by the sympathetic nervous system via alpha-adrenergic receptors of the vascular smooth muscle, predominantly the alpha 2 receptors, leading to a theory of effect of alpha blockers. Angiotensin converting enzyme (ACE) inhibitors and angiotensin-II receptor antagonists inhibit the vasoconstrictor effect of angiotensin-II on vascular smooth muscle. A platelet release of serotonin contributing to the vasospasm has been observed in scleroderma-related Raynaud's phenomenon, leading to the theory of effect of serotonergic S2-receptor antagonists (ketanserin) and serotonin converting enzyme inhibitors (SSRI) (Block 2001; Medicines.org.uk). For most other drugs, their vasodilatory effect is known, but not how this may influence the symptoms of Raynaud's phenomenon.

Few drugs are licensed for the treatment of primary Raynaud's phenomenon. Many studies on the treatment of Raynaud's phenomenon have restricted participants to persons with secondary Raynaud's phenomenon. Because of the different underlying aetiology and pathophysiology of primary and 
secondary Raynaud's phenomenon, it is probable that the treatment effect will be different in the two groups. Many of the possible alternative drugs also have adverse effects, and this may restrict their possible long-term use by otherwise healthy and often young people.

\section{O B JECT IVES}

To assess the effects of various drugs with vasodilator effects on primary Raynaud's phenomenon as determined by the frequency, duration and severity of vasospastic attacks.

\section{METHODS}

\section{Criteria for considering studies for this review Types of studies}

All randomised controlled trials comparing a drug with vasodilator effects with placebo or alternative drug therapy for the treatment of primary Raynaud's phenomenon were considered eligible. Any method of randomisation was considered. Both parallel and crossover studies were included. There were no language restrictions. Treatment with calcium channel blockers will be addressed in another Cochrane systematic review (Herrick 2008).

\section{Types of participants}

Trials involving participants with primary Raynaud's phenomenon were included. Trials with a mixture of primary and secondary Raynaud's phenomenon were included if participants with primary Raynaud's phenomenon could be identified and the data could be extracted for this subgroup. The study authors' definition of primary Raynaud's phenomenon was accepted unless details in the description of clinical characteristics of the participants with primary Raynaud's phenomenon did not comply with current diagnostic criteria.

\section{Types of interventions}

Trials with oral administration of any drugs with vasodilator effects compared with placebo or other drugs were identified. This included drugs registered for the treatment of cardiovascular diseases, Chapter 2 in the British National Formulary (BNF) (BNF53) and Class $C$ in the Anatomical Therapeutical Classification (ATC) system (ATC classification; BNF53). Other drugs with vasodilator effects that have been suggested for the treatment of Raynaud's phenomenon, but that are primarily used for non-cardiovascular diseases, were also included. See additional table for details of drugs with vasodilator effects (Table 1) and search strategies used (Appendix 1; Appendix 2; Appendix 3). All studies including treatment with, or comparison with, calcium channel blockers, or alternative (complementary) medicine were excluded.

Owing to the daily and seasonal variations in frequency and duration of attacks, trials with treatments administered only once (single dose trials) or of less than one week's duration were excluded. Studies involving intravenous treatment of drugs were excluded because of the generally benign presentation of primary Raynaud's phenomenon and the need for simple, symptomatic and prophylactic treatment for otherwise healthy people.

\section{Types of outcome measures}

\section{Primary outcomes}

- frequency of attacks.

\section{Secondary outcomes}

- duration of attacks;

- severity of symptoms, measured on validated scales, for example Visual Analogue Scales or Likert scales;

- quality of life scores;

- adverse events including withdrawals.

\section{Search methods for identification of studies}

There were no restrictions on language.

\section{Electronic searches}

The Cochrane Peripheral Vascular Diseases Group Trials Search Co-ordinator (TSC) searched the Specialised Register (last searched May 2012) and the Cochrane Central Register of Controlled Trials (CENTRAL) 2012, Issue 4, part of The Cochrane Library, www.thecochranelibrary.com for publications describing randomised controlled trials of drugs with vasodilator effects versus placebo or alternative drug therapy for the treatment of primary Raynaud's phenomenon. See Appendix 1 for details of the search strategy used to search CENTRAL. The Specialised Register is maintained by the TSC and is constructed from weekly electronic searches of MEDLINE, EMBASE, CINAHL, AMED, and through handsearching relevant journals. The full list of the databases, journals and conference proceedings which have been searched, as well as the search strategies used are described in the Specialised Register section of the Cochrane Peripheral Vascular Diseases Group module in The Cochrane Library (www.thecochranelibrary.com).

The following trial databases were searched by the TSC for details of ongoing and unpublished studies using the term Raynaud:

- World Health Organization International Clinical Trials Registry http://apps.who.int/trialsearch/;

- ClinicalTrials.gov http://clinicaltrials.gov/;

- Current Controlled Trials http://www.controlled-trials.com/.

2008 version

The review authors searched MEDLINE (January 1966 to July 2007) (Appendix 2) and EMBASE (January 1980 to July 2007) (Appendix 3). The search included drugs with vasodilator effects registered in the BNF53 for the treatment of cardiovascular diseases and the class $C$ (cardiovascular diseases) in the ATC classification (ATC classification; BNF53) (see Table 1). Generic and proprietary names were taken from BNF53.

\section{Searching other resources}

\section{8 version}

The review authors searched for unpublished and ongoing trials in www.controlled-trials.com and www.trialscentral.org. They searched for references within identified studies and cited references in the Web of Science and contacted one specialist on Raynaud's phenomenon for details of unpublished and 
ongoing trials. Pharmaceutical companies marketing 20 of the identified drugs in trials were contacted and were asked to provide information on both published and unpublished trials and information on unregistered drugs identified in the searches.

\section{Data collection and analysis}

\section{Selection of studies}

Two members of the review team (MS and either BV or JM) identified trials for possible inclusion and independently reviewed the abstracts. Full-text articles were obtained and, if necessary, translated if the above mentioned inclusion criteria were met, or if the titles or abstracts did not clarify inclusion or exclusion criteria. Disagreements were resolved by discussion and consensus.

One member of the review team (MS or BV) contacted 25 trial authors or co-authors for additional information on the articles which did not provide sufficient information to determine whether they should be included or excluded. This included all articles where data from subgroups could not be identified. Postal and email addresses were obtained by searching the relevant article, the author's or co-authors' most recent reference in Web of Science and 'Google'. Replies were received from nine. One author was able to provide additional information but the other authors could not provide additional information because of lost or otherwise unavailable data. One pharmaceutical company was contacted for additional information.

\section{Data extraction and management}

Each study was reviewed by two members of the review team (MS and either BV or JM) independently, and the data from the included studies were extracted using the Cochrane PVD Group 'Data Extraction Table'. This included method of allocation, degree of blinding, power calculations, exclusions post-randomisation, losses to follow up, source of funding, country where the study was undertaken, number of participants, age and sex of participants, inclusion and exclusion criteria, treatment, control group, duration of study, and outcome measures. One study had multiple publications. In this case, we extracted the data from the most complete reported study (Ettinger 1984). We resolved disagreements by discussion and consensus.

\section{Assessment of methodological quality of included studies}

Two members of the review team (MS and BV) independently assessed the methodological quality of the included studies using the methods described by Jadad 1996 and Schulz 1995.

The Jadad method assigns scores to each study based on the three questions:

1. Was the study described as randomised?

2. Was the study described as double blind?

3. Was there a description of withdrawals and dropouts?

A score of one point was given if the answer to the question was 'yes' and zero if the answer was 'no'. An additional one point was given to questions one and two if the method was described and was appropriate. One point was deducted if the method was described and was inappropriate.

The Schulz study found that trials which reported treatment allocation concealment inadequately or unclearly yielded larger estimates of treatment effects than when they were adequately reported. A score of $A$ was given when treatment allocation was adequately concealed and clearly stated. A score of B was given if allocation was unclear; this included allocation stated as random but no further details were given. A score of $\mathrm{C}$ was given if treatment allocation was definitely inadequate. $D$ indicated that the score was not assigned.

In addition, we undertook a general assessment of each study. This included power calculations, the use of adequate statistical methods, intention-to-treat analysis, and a description of characteristics of intervention and treatment groups. This was used to assess the quality of the studies. However, no cut-off points were defined and subsequently used as criteria for inclusion or exclusion of studies. Disagreement between the authors was resolved by consensus.

\section{Statistical analysis}

We performed statistical analysis according to the statistical guidelines provided for authors by the Cochrane PVD Group and from the Cochrane Handbook for Systematic Reviews of Interventions 4.2.6 (Higgins 2006). Statistical analyses were carried out using the Review Manager software (RevMan 4.2) provided by The Cochrane Collaboration. Paired t-tests were carried out according to the methods described in Campbell and Machin (Campbell 1999).

In all the studies, results were presented as mean values for whole treatment periods, and these were used as post-intervention values. Analyses were carried out using the difference between the treatment and control group's post-intervention values. No changes from baseline values were included in the analyses. Rates for frequency of attacks were recalculated to attacks per week to allow for easier comparison between the trials. Conversion between standard errors (SE) and standard deviations (SD) was carried out when necessary.

Two trials measured outcomes on more than one occasion. Le Quentrec 1991 measured outcomes at two, four and six months, using the same dose during the whole treatment period. The differences in outcome between four and six months were minor. We used the six-month outcomes in this review. Vayssairat 1996 measured outcomes after Phase II, $20 \mu \mathrm{g}$ three times daily, and Phase III, $40 \mu \mathrm{g}$ three times daily. We used the latter outcomes in this review. Additional information for the Vayssairat 1996 study clarified that intention-to-treat analyses had been carried out. For all other trials with exclusions, withdrawals or losses to follow up, no intention-to-treat analysis had been discussed or presented. In these, the calculations of the results for the cross-over trials had been based on the participants who completed both treatment arms. No data were re-analysed according to the principles of intention-to-treat.

Many trials reported outcomes using different scales, especially for severity. Because of the limited results, the data could not be pooled and it was not necessary to convert data to standardised mean differences.

Because of the limited results, numbers needed to treat (NNT) or subgroup analyses were not carried out. A funnel plot to assess the possibility of publication bias could not be constructed because of the lack of comparable studies. 


\section{Parallel design trials}

Two trials had a parallel design. We analysed dichotomous data using relative risk (RR) as a summary statistic with $95 \%$ confidence interval $(\mathrm{Cl})$. For continuous data, we extracted mean and standard deviation values for each treatment period and analysed using the weighted mean difference (WMD) with $95 \% \mathrm{Cl}$ intervals as summary statistic.

\section{Cross-over design trials}

Six trials had a cross-over design. Where possible, we analysed the effect measures for continuous data as mean differences $(95 \% \mathrm{Cl})$ using the results from paired analyses. The results were available directly from the trial reports (Rustin 1987), by calculations from individual data using the paired t-test (Ettinger 1984; Madsen 1984) or by calculating standard errors (SE) from the reported confidence interval (Challenor 1991, outcome frequency of attacks). We entered the results into RevMan using the generic inverse variance method.

Two studies presented the results as means \pm SE for each treatment group separately (Challenor 1991, outcome improvement; van de Wal 1987). No data were presented which allowed conversion to standard deviations (SD) of paired observations. We analysed the data using weighted mean differences (WMD) $(95 \% \mathrm{Cl})$ as a summary statistic as though a parallel design had been used. According to Elbourne 2002 and Higgins 2006, treating data from cross-over trials as parallel group trials ignores the fact that the same patients appear in both arms of the study. This may lead to a unit of analysis error, and the resulting confidence intervals may be too wide.

Three cross-over trials presented results as dichotomous data. Paired analyses could not be carried out because of the lack of reported data. Correlation coefficients could not be calculated because there were only single trials for each drug. For two trials the results are reported with no further analyses (Madsen 1984; van de Wal 1987). For one study (Jaffe 1980) the results from the trial author's own paired analysis is presented (outcome fewer attacks). We analysed the results for adverse events for this study using relative risk $(95 \% \mathrm{Cl})$ as a summary statistic, as no data for paired analysis were presented (Jaffe 1980).

No analyses for cross-over trials were carried out using results from only the first treatment period. Of the six cross-over trials, only one included a wash-out period (Ettinger 1984). Calculations for carryover or period effect were not carried out.

\section{Data synthesis}

The results of three cross-over studies were combined in a metaanalysis. These compared the ACE inhibitors captopril (Madsen 1984; Rustin 1987) and enalapril (Challenor 1991) with placebo for the outcome 'frequency of attacks'. We entered the data into RevMan using the generic inverse variance method. A randomeffects model (DerSimonian 1986) was used because captopril and enalapril belong to the same class of drugs, but have different pharmacological properties, and the duration of the treatment periods were unequal. The Challenor 1991 study was given a high weight compared to the other studies because of a small standard error. We therefore performed a sensitivity analysis excluding the enalapril trial from the meta-analysis. Because of the similarity between the two captopril trials concerning participants, dose, length of treatment and lack of wash-out period, we used a fixedeffect model.

Results for the other drugs are presented separately because of the lack of pharmacological similarity, and no other assessment of heterogeneity was relevant.

\section{RE S U L T S}

\section{Description of studies}

\section{Results of the search}

There were 167 citations retrieved from the CENTRAL search, 76 from the Specialised Register and 137 citations from the search of the clinical trials databases. Of these there were 12 citations to 8 studies which were included in the review, 80 citations to 77 studies which were excluded and one ongoing study.

More than 30 different drugs with vasodilator effects were identified, although some were non-oral formulations. The included studies represented seven different drugs.

\section{Included studies}

There were 12 citations to 8 studies included in the review.

See the 'Characteristics of included studies' table.

A total of eight studies were included with a total of 290 participants. The largest study (Vayssairat 1996) involved 125 participants. One study had six participants, and the remaining had less than 41 participants. The studies were published between 1980 and 1996.

\section{Types of participants}

One trial had a mixture of participants with primary and secondary Raynaud's phenomenon (Ettinger 1984). One had a mixture of participants with primary Raynaud's phenomenon and chilblains (Jaffe 1980). However, this trial was conducted and the results were presented completely separately for the two groups. The remaining trials included only participants with primary Raynaud's phenomenon. All studies defined primary and secondary Raynaud's phenomenon according to criteria, but the degree of detail varied substantially. The baseline frequency of attacks was six to 24 per week in all trials except one. This trial reported a mean of 91 attacks per week (van de Wal 1987). This high frequency was also discussed by the trial author, and was therefore not likely to be due to an error in reporting the data. Ten of 41 participants in this trial had previously undergone thoracic sympathectomy, reflecting severe disease.

One study had only female participants; the others had more female than male participants, reflecting the prevalence of Raynaud's phenomenon in the population. The age range was identical in all studies, having both young (around 20 years of age) and older (around 70 years of age) participants. The setting was general practice in one, specialist outpatient clinic in four and not described in three trials. All trials were conducted in the winter season. The prevalence of smoking was reported by some authors, and varied between $14 \%$ and $51 \%$. The studies differed in the details and description of their exclusion criteria. 


\section{Interventions}

See additional Table 2 and Table 3.

The studies represented seven different drugs. There were two trials with captopril and single trials on each of the following drugs: beraprost, buflomedil, enalapril, dazoxiben, ketanserin and moxisylyte (thymoxamine). Seven trials compared a drug with placebo. One study was a cross-over trial comparing dazoxiben with a calcium channel blocker and placebo (Ettinger 1984). The calcium channel blocker data were not used.

\section{Length of studies}

The duration of the treatment periods varied from two weeks to six months. Two studies had a two-week run-in period, one study had a four-week run-in period, all with single-blind placebo treatment. One study had a two-week run-in with no treatment. Four studies had no run-in period.

\section{Outcomes}

Frequency, duration and severity were recorded in diaries. Frequency of attacks was reported in all studies. Most studies also had some measure of severity. However, the scales used for severity differed substantially. Measures of duration were minutes per attack or total minutes per day. No study included quality of life measures. Adverse events and withdrawals were recorded in all trials.

Most studies also had different objective outcomes not included in this review.

\section{Excluded studies}

There were 80 citations to 77 studies which were excluded.

See 'Characteristics of excluded studies' Table 2, and Table 3.

Of the 77 studies in the exclusion list, 28 did not present data which allowed data extraction and subgroup analyses for participants with primary Raynaud's phenomenon. Ten were not randomised controlled trials; most were open studies or with no control group. In 11 trials the participants did not meet the inclusion criteria, mainly because all participants had secondary Raynaud's phenomenon. In six trials the drug was administered only once (single dose trials), and in 16 the treatments were not oral; these were topical applications, intradermal injections and intravenous treatments. In seven trials the outcomes were not relevant for this review, mostly because subjective outcomes were not included. Some lacked any description or definition of the outcome and how the data were collected. In three studies the results were presented unclearly and could not be used. No additional information could be obtained. Of the excluded studies, at least 45 had less than 20 participants with primary Raynaud's phenomenon, and many of these less than 10 participants. We excluded six trials because a comparison with a calcium channel blocker was made. Many studies had more than one reason for exclusion.

Although the trial authors' definition of primary Raynaud's phenomenon was accepted irrespective of details in definition of criteria, one trial (Cleophas 1984) was excluded because it specified that eight of 20 participants in the primary Raynaud's phenomenon group had positive anti nuclear antibodies (ANA).

Oral vasodilators for primary Raynaud's phenomenon (Review)

Copyright (c) 2012 The Cochrane Collaboration. Published by John Wiley \& Sons, Ltd.
This is an exclusion criterion for the diagnosis of primary Raynaud's phenomenon.

The following classes of drugs or single drugs were not represented in the included studies: Alpha adrenoreceptor blocking drugs, angiotensin II receptor antagonists, nitrates, inositol nicotinate, naftidrofuryl oxalate, cilostazol, SSRI's and antihistamines (see additional Table 2 and Table 3 ).

\section{Risk of bias in included studies}

See also additional Table 4.

All included studies were described as randomised and double blinded. Two trials had an allocation score $A$ and a Jadad score of five. The remaining six trials had an allocation score $B$ and a Jadad score of three. For these six studies the description of the methods for allocation, randomisation and blinding was lacking or inadequate. We could not assess the quality of the methods.

\section{Follow up and exclusions}

No study specifically discussed intention-to-treat analysis. However, additional information confirming this was supplied by one author (Vayssairat 1996). This study had 14\% loss to follow up after randomisation. Six studies had none or one to two exclusions.

The Jaffe 1980 study was a cross-over study which randomised 41 participants. However, only 33 completed the study and were included in the results for frequency of attacks. Loss to follow up was $20 \%$. For severity and duration of attacks, data from only 25 versus 26 participants could be used. This was explained by low precision in the reporting and may have been caused by poorly defined outcomes. Loss to follow up for these outcomes was 37 to $39 \%$.

\section{Power calculations}

Only one study presented sample size calculations (Vayssairat 1996). The study included fewer participants than the numbers estimated (118 after randomisation versus 160). Only 102 participants completed the study. The treatment effect turned out to be very small compared with the estimated $50 \%$ difference in the number of attacks between the two treatment groups on which the sample size calculations were based. The study was therefore underpowered. Generally, the sample sizes in the studies were small.

\section{Cross-over studies, carry-over and period effect}

Five cross-over studies did not include a wash-out period (Challenor 1991; Jaffe 1980; Madsen 1984; Rustin 1987; van de Wal 1987). Ettinger 1984 included a one-week wash-out period, and placebo as one of the three treatment arms. The drugs had different pharmacological properties. It is probable that a carry-over effect, i.e. effect of the active treatment continuing into the next placebo period, may have affected the final results in some studies. Some authors reported testing for period and carry-over effect.

\section{Reporting of outcomes}

A variety of scales were used for severity. This included 0 to 4 scale, 1 to 3 scale, $100 \mathrm{~mm}$ or $10 \mathrm{~cm}$ Visual Analogue Scale, and severity score $=$ frequency times duration. Scales were generally described. However, in some trials there was a lack of definition (Rustin 1987; van de Wal 1987), or inconsistency (Challenor 1991) 
between the scale described in methods section and the reported results. Therefore, these outcomes were excluded from the review. Two studies did not report results for outcomes described in the methods section (Challenor 1991; Rustin 1987). Some data were reported as binary data or short ordinal scales, as variations of improved-unchanged-worse. The validation and definitions used for these were not described or discussed in the studies.

\section{Funding}

Six trials had support from a pharmaceutical company; the remaining two did not state their source of funding.

\section{Effects of interventions}

The results are presented for each drug separately.

\section{Angiotensin Converting Enzyme (ACE) inhibitors}

Captopril (ATC code C09AA01) and Enalapril (ATC code C09AA02) Three studies comparing captopril $25 \mathrm{mg}$ three times daily (Madsen 1984; Rustin 1987) or enalapril 20 mg once daily (Challenor 1991) with placebo were included. All were cross-over studies. All 45 participants had primary Raynaud's phenomenon. The duration of both captopril trials was two periods of six weeks and the enalapril trial was two periods of four weeks.

For the meta-analysis of the ACE inhibitors captopril and enalapril there was a statistically significant difference in the mean number of attacks per week, with higher frequency on treatment $(0.79$ attacks; 95\% Confidence interval (Cl) 0.43 to 1.16). After the Challenor 1991 study was excluded from the analysis, the difference between captopril and placebo was non-significant (difference in means $0.64,95 \% \mathrm{Cl}-1.11$ to 2.38 ).

Enalapril alone was associated with a small increase in the frequency of attacks per week. The difference in the mean number of attacks per week was $0.80(95 \% \mathrm{Cl} 0.43$ to 1.17$)$, favouring placebo. There was a non-significant difference on the subjective assessment of improvement, favouring placebo $(10 \mathrm{~cm}$ Visual Analogue Scale) (weighted mean difference (WMD) 1.10; $95 \% \mathrm{Cl}$ -0.01 to 2.21). Thirteen of 20 participants experienced more attacks on enalapril than on placebo.

One study reported duration per attack. There was a non-significant difference favouring captopril $(-0.54$ minutes; $95 \% \mathrm{Cl}-2.42$ to 1.34) (Rustin 1987). The Madsen 1984 study reported three of 10 improved in the captopril group and two of 10 improved in placebo group. The remaining participants in each group were unchanged.

There were no withdrawals in the captopril studies and one in the enalapril study. This withdrawal was for personal reasons and was deemed unrelated to the treatment by the authors. There were no reported side effects in the Rustin 1987 trial. Madsen 1984 reported one participant with nausea the first week and one with pain in the calf muscle during the whole intervention period in the captopril group, and no side effects in the placebo group. In the Challenor 1991 trial nine participants receiving enalapril and eight participants receiving placebo reported side effects. Dizziness was most commonly reported, but all side effects were transient.

\section{Buflomedil}

(ATC code C04AX20, other peripheral vasodilators)
One study was included (Le Quentrec 1991). This had a parallel design, comparing buflomedil $300 \mathrm{mg}$ twice daily with placebo. All 31 participants had primary Raynaud's phenomenon. The duration of the trial was six months, with outcomes measured at two, four and six months. We used the results from the six months follow up in this review.

The difference in the frequency of attacks per week favoured buflomedil, however, the confidence interval was wide and close to non-significant. (WMD -8.82; 95\% Cl -17.55 to -0.09). Baseline frequency was 24 attacks per week in both intervention groups.

The difference in the mean severity score favoured buflomedil, but this was not statistically significant (WMD $-0.41 ; 95 \% \mathrm{Cl}-0.84$ to 0.02).

There were no withdrawals from the trial. Two side effects were reported in the placebo group (gastric upset) and three in the buflomedil group (gastric burning, vertigo, hot flush). The side effects disappeared spontaneously with neither modification nor withdrawal of treatment.

\section{Beraprost}

(ATC code B01AC19: platelet aggregation inhibitors excluding heparin; prostacyclin analogue)

One study was included (Vayssairat 1996). This was a parallel design trial comparing beraprost $40 \mu \mathrm{g}$ three times daily with placebo (phase III). All 125 participants had primary Raynaud's phenomenon. We used the results from Phase III of the trial.

Although both treatment groups had a reduction of attacks per week, this was higher in the placebo group. The difference was nonsignificant (WMD 2.0; 95\% Cl -0.20 to 4.20). Baseline values were 11 to 12 attacks per week. Vayssairat found that the reduction of attacks from baseline was $44 \%$ in the placebo group and $37 \%$ in the beraprost group.

There was no evidence of effect on the severity of attacks, measured by the severity score (WMD $-0.06 ; 95 \% \mathrm{Cl}-0.32$ to 0.20 ) or the disability score (WMD 3.0; $95 \% \mathrm{Cl}-6.75$ to 12.75 ). No differences were statistically significant.

A total of nine participants in the beraprost group and seven in the placebo group withdrew, four participants in the beraprost group and three in the placebo group because of side effects. Six were lost to follow up, and three withdrew because of personal reasons. These were equally distributed between the intervention groups. There were significantly more side effects in the beraprost group (relative risk (RR) 1.62; $95 \% \mathrm{Cl} 1.08$ to 2.43 ). Headache was reported by 16 of 59 in the treatment group and one of 59 in the placebo group.

\section{Dazoxiben}

(Thromboxane synthetase inhibitor, no ATC code)

One trial was included (Ettinger 1984). This was a cross-over trial comparing dazoxiben $100 \mathrm{mg}$ four times daily with nifedipine and placebo. We did not use the data from the nifedipine arm. Six of 25 participants had primary Raynaud's phenomenon, but one was withdrawn because of inadequate compliance. Only results for the frequency of attacks could be used; the other outcomes had no subgroup data. 
There was no evidence of the effect of dazoxiben compared with placebo. The mean frequency of attacks per week during intervention was $12.0 \pm 6.02$ (SD) in the dazoxiben group and $11.2 \pm$ 8.15 (SD) in the placebo group. The non-significant difference was 0.8 attacks per week, favouring placebo (difference in means 0.8 ; $95 \% \mathrm{Cl}-2.88$ to 4.48$)$.

\section{Ketanserin}

(ATC code C02KD01 other antihypertensives, serotonin antagonists)

One study was included, a cross-over trial comparing ketanserin $40 \mathrm{mg}$ twice daily with placebo (van de Wal 1987). All 41 participants had primary Raynaud's phenomenon. The duration of each treatment period was six weeks.

There was no evidence of the effect of ketanserin on the frequency or duration of attacks. The difference in number of attacks per week was 14, favouring ketanserin (WMD $-14.0 ; 95 \% \mathrm{Cl}-33.40$ to 5.40). The difference in the duration of attacks was four minutes per day, favouring ketanserin (WMD $-4.0 ; 95 \% \mathrm{Cl}-19.30$ to 11.30 ). These differences were not statistically significant. However, there was a significant difference between the two groups in the severity score, favouring ketanserin (WMD $-133.0 ; 95 \% \mathrm{Cl}-202.27$ to -63.73 ). Subjective feeling of improvement was reported by 24 participants after ketanserin treatment and 14 after placebo.

Twenty participants in the ketanserin group and 13 in the placebo group reported adverse events. The difference was non-significant (RR 1.54; $95 \% \mathrm{Cl} 0.89$ to 2.65). Dizziness, headache and dry mouth were reported more frequently in the treatment group.

\section{Moxisylyte (Thymoxamine)}

(ATC code C04AX10 other peripheral vasodilators)

One study comparing moxisylyte (thymoxamine) $40 \mathrm{mg}$ four times daily with placebo was included (Jaffe 1980). This study included 41 participants, all with primary Raynaud's phenomenon. The study had a cross-over design. Each treatment period was two weeks.

Thirty three participants completed both treatment arms for the outcome 'frequency of attacks'. Nineteen participants had fewer attacks during the moxisylyte period and 10 during the placebo period. Four participants had an equal number of attacks in each period. The difference was statistically significant, favouring moxisylyte ( $P<0.02$, Wilcoxon matched pairs signed rank test).

Seven participants reported more severe attacks during the moxisylyte period compared with 18 during placebo administration. The remaining participants were unchanged or had less severe attacks. Fifteen participants recorded shorter total duration while on moxisylyte, and nine had shorter duration on placebo. Because data were unavailable for $37 \%$ to $39 \%$ of the participants, we did not carry out any statistical analyses.

One participant was withdrawn from the treatment group because of an embolus deemed by the trial authors not to be drug related, and three participants in the placebo group were withdrawn because of side effects. A total of 13 participants in the moxisylyte group and three in the placebo group reported adverse events. Therefore, adverse events were significantly more frequent in the moxisylyte group (RR 4.33; 95\% Cl 1.36 to 13.81). Dyspepsia, heartburn, flushing and changes in taste were reported by two or more participants in the treatment group and none in the placebo group.

\section{DISCUSSION}

This review has summarised the evidence for the treatment of primary Raynaud's phenomenon with drugs with vasodilator effects other than calcium channel blockers. Of 85 identified trials and more than 30 different drugs, eight studies were included, with a total of 290 participants. The studies represented seven different drugs, all compared with placebo. The drugs were: captopril, enalapril, buflomedil, beraprost, dazoxiben, ketanserin and moxisylyte (thymoxamine).

- The meta-analysis of the ACE inhibitors captopril and enalapril, and enalapril alone, showed these drugs to be associated with a small increase in the frequency of attacks per week compared with placebo. For captopril alone, the difference between the treatment groups for frequency and duration of attacks was non-significant (Challenor 1991; Madsen 1984; Rustin 1987).

- The difference between buflomedil and placebo on the frequency of attacks per week was significant, favouring buflomedil. However, the small sample size resulted in a wide confidence interval and low precision. The difference in the severity score was non-significant (Le Quentrec 1991).

- There was no evidence of the effect of beraprost compared with placebo on the frequency and severity of attacks and the disability score. All results were non-significant (Vayssairat 1996).

- There was no evidence of the effect of dazoxiben compared with placebo on the frequency of attacks. The difference was nonsignificant, and the precision of the results was low, with a wide confidence interval (Ettinger 1984).

- There was no evidence of the effect of ketanserin on the frequency or duration of attacks, although the result for the severity score significantly favoured ketanserin. For all outcomes, the precision of the results was low because of very wide confidence intervals (van de Wal 1987).

- There was a statistically significant effect in favour of moxisylyte compared with placebo on the number of participants experiencing fewer attacks (Jaffe 1980).

- Seven studies reported adverse events. Beraprost (Vayssairat 1996) and moxisylyte (Jaffe 1980) gave significantly more side effects than placebo. For the other drugs there were few reported adverse events, or the differences were nonsignificant.

- The following classes of drugs or single drugs with vasodilator effects were not represented in the included studies: Alpha adrenoreceptor blocking drugs, angiotensin II receptor antagonists, nitrates, inositol nicotinate, naftidrofuryl, cilostazol, SSRI's and antihistamines.

None of the studies discussed 'clinically important effect' as opposed to 'statistically significant effect'. A review on calcium channel blockers for primary Raynaud's phenomenon arbitrarily defined a $30 \%$ reduction of symptoms as clinically important (Thompson 2005). Some researchers on pain have defined clinically important results as a $50 \%$, or alternatively $30 \%$, reduction on a validated scale (Farrar 2000). When this is added to a high placebo response, reported by Vayssairat 1996 to be close to $50 \%$ in some studies, the overall effect must be very high to 
obtain a clinically significant result. When subjective outcomes in the included studies were reported as dichotomous data, for example 'improved versus unchanged or worse' or 'fewer versus unchanged or more attacks', without described or validated scales, the clinical importance of the results was impossible to assess. This applied to moxisylyte (Jaffe 1980) and captopril (Madsen 1984). For the studies that reported severity outcome, none used the same scale. The description and assessments of validity of the scales used was lacking or inadequate in all studies. This made evaluation of 'clinically significant results' impossible in the studies with statistically significant results. No drug had statistically significant differences between the intervention groups on all reported outcomes, and this reduced the clinical significance of single results.

Small sample sizes resulted in low statistical precision and wide confidence intervals. Only one study reported sample size calculations (Vayssairat 1996). This was based on an estimated treatment effect which was very high compared to the actual result obtained, and the study was underpowered. The other studies had very small sample sizes. Single studies on each drug did not allow pooling of results for larger sample sizes and higher precision.

The advantage of a cross-over design is that the interventions are evaluated on the same participants, and the resulting withinsubject differences are usually smaller than the within-group differences. Significant results can be obtained with smaller sample sizes than studies with parallel design. However, as the results in some trials were inadequately reported, in order to be used in this review the data had to be presented as though the studies were designed as parallel trials, with the subsequent loss of power (Challenor 1991; Madsen 1984; van de Wal 1987). The advantages of the cross-over design were therefore lost (Elbourne 2002). Lack of wash-out periods with subsequent carry over may also have reduced the differences between treatment and placebo in the cross-over trials.

In all the included studies, the results were reported as mean values for whole treatment periods. Depending on the drug's pharmacological properties, especially when steady state takes longer to reach and the onset of effect is slow, any differences between the two intervention groups may be reduced when this method is used.

Although all participants were diagnosed with primary Raynaud's phenomenon, there may have been high degrees of heterogeneity within the studies. Any effects in subgroups would have been masked by a summary statistic, especially mean values. The small sample sizes and the few studies included did not allow subgroup analyses.

All these issues will, in different ways, have affected the final results in the studies. The probability of finding significant statistical and clinical effects has been reduced.

The defined outcomes for this review were only subjective outcomes. This is because primary Raynaud's phenomenon rarely leads to permanent tissue damage. Treatment is prophylactic and symptomatic and aimed directly at reducing the patient's symptoms. Objective measurements may be surrogate measures, and how the results relate to the patient's subjective symptoms may not be clear. Different methods have been developed over the years according to technical advances, which would make comparison of results from older and more recent studies difficult or impossible.

All the studies reported adverse events, but the clinical significance of these was difficult to assess because of the short trial durations and the many reported adverse events in the placebo groups. No study included follow up after discontinuation of treatment to specifically address the side effects of the discontinuation, although cross-over studies indirectly would register them because they would appear as placebo side effects for the comparison group which had placebo in the second period.

The intervention in this review was defined very broadly. This was based on an expected limited result, as reported by other reviews. Although very many drugs were included in the search strategy, it is possible that some trials may have been missed because the drugs were reported under other proprietary names, or were not described as 'vasodilator' in the title or text. There may be disagreements as to which drugs should be defined as 'vasodilator'. However, the general search term 'vasodilator agent' was meant to cover any drug that has not been specifically listed. The final number of included studies and the drugs they represented was very limited. It may be argued that they were selected by chance, because they happened to comply with the inclusion and exclusion criteria for this review, and not because they were the best in their group. However, a major part of the relevant randomised controlled trials did not present data for subgroup analysis. The result might have been different if it was possible to include the raw data for these studies. All the authors who replied to our enquiry stated that the raw data were either lost or destroyed. This may have been the case for most of the other studies, which were more than 15 to 20 years old. The pharmaceutical companies could give no additional information that could change the result. Many of the pharmaceutical companies which supported the included studies have ceased to exist or have merged with larger companies, thus making it difficult to find old data. It is probable that the included studies are representative for the methodological quality of trials in the 1980's, which means that the results in most other studies would not have been accepted without many reservations. The external validity, and subsequently the value of these studies will be reduced when compared to research based on current diagnostic procedures and demand for documentation according to the CONSORT statement (Moher 2001).

An important result of this review is the identification of the many drugs which have been the object of trials, and the lack of evidence for their use for the treatment of primary Raynaud's phenomenon. The poor quality of the few included studies reduced the value of any significant results.

The results of this review confirm the results in other reviews: there is no, or very limited evidence for treatment of primary Raynaud's phenomenon with drugs with vasodilator effects (Distler 2006; Pope 2006; Prodigy 2006).

\section{AUTHORS' CONCLUSIONS}

\section{Implications for practice}

The overall result of this review is that there is no evidence of the effect of any drugs with vasodilator effects (excluding calcium channel blockers which were not considered in this review) on primary Raynaud's phenomenon. 


\section{Implications for research}

Based on the results of this review, research is required on the treatment of primary Raynaud's phenomenon, and more knowledge about alternatives to calcium channel blockers is essential. This includes safety and efficacy for long-term use, including adverse effects and the cost of treatment alternatives.

It is important that studies are adequately powered, taking account of the methodological challenges of high placebo responses and the natural fluctuations of symptoms. Methods must be developed that do not mask or reduce any possible effects of the different interventions. Standardisation of outcome measures and the use of validated scales is essential for the comparability between studies. An example of this is the 'Raynaud Condition Score', although this has been developed and validated for secondary Raynaud's phenomenon (Merkel 2002). It is essential to agree on a definition of clinically important effects according to any validated scales that are used (Farrar 2000).

Six of the eight included studies were supported by pharmaceutical companies, for the remaining two this was not described. Studies sponsored by pharmaceutical companies have been shown to be more likely to have outcomes favouring the product of the sponsoring company than studies funded by other sources (Lexchin 2003). It is essential for future research that the source of support is explicitly stated, and that every effort is taken to develop standards for research funded by pharmaceutical companies or other agencies with commercial interests in the results (Lexchin 2003).

Reporting of trials using standards such as the recommendations of the CONSORT statement is likely to influence the quality of the conducted trials and facilitate the interpretation, evaluation, applicability and comparability of their results (Moher 2001).

\section{A C K N O WLEDGEMENTS}

For the 2008 version of the review the authors thanked Professor Gerry Fowkes, Mrs Heather Maxwell, Dr Karen Welch, Professor Gordon Murray and Dr Janet Wale, Consumer Network for her contribution to the Plain Language Summary. Dr Bergljot Vinjar also thanked Møre and Romsdal County, Norway and WHO through Norwegian Directorate for Health and Social Affairs, Norway for financial support for the review.

For this update of the review, we thank Dr Bergljot Vinjar for her invaluable work as an author of the 2008 version of the review. 


\section{R E F E R E N C E S}

\section{References to studies included in this review}

Challenor 1991 \{published data only\}

Challenor VF, Waller DG, Hayward RA, Griffin MJ, Roath OS. Clinical and physiological assessment of angiotensin-converting enzyme inhibition in primary Raynaud's phenomenon. British Journal of Clinical Pharmacology 1989;28(6):739P-740P.

* Challenor VF, Waller DG, Hayward RA, Griffin MJ, Roath OS. Subjective and objective assessment of enalapril in primary Raynaud's phenomenon. British Journal of Clinical Pharmacology 1991;31(4):477-80.

\section{Ettinger 1984 \{published data only\}}

* Ettinger WH, Wise RA, Schaffhauser D, Wigley FM. Controlled double-blind trial of dazoxiben and nifedipine in the treatment of Raynaud's phenomenon. American Journal of Medicine 1984;77(3):451-6.

Malamet R, Wise RA, Ettinger WH, Wigley FM. Nifedipine in the treatment of Raynaud's phenomenon. Evidence for inhibition of platelet activation. American Journal of Medicine 1984;78(4):602-8.

Wigley FM, Malamet R, Wise RA. Reproducibility of cold provocation in patients with Raynaud's Phenomenon. Journal of Rheumatology 1987;14(4):751-5.

Jaffe 1980 \{published data only\}

Jaffe GV, Grimshaw JJ. Thymoxamine for Raynaud's disease and chilblains. British Journal of Clinical Practice 1980;34(11-12):343-6.

\section{Le Quentrec 1991 \{published data only\}}

Le Quentrec P, Lefebvre ML. Double-blind placebo-controlled trial of buflomedil in the treatment of Raynaud's phenomenon: six-month follow-up. Angiology 1991;42(4):289-95.

\section{Madsen 1984 \{published data only\}}

Madsen JL, Hvidt S. [Raynaud's disease treated with captopril (Capoten). A randomized double-blind cross-over study. Ugeskrift for Laeger 1984;146(36):2695-7.

\section{Rustin 1987 \{published data only\}}

Rustin MH, Almond NE, Beacham JA, Brooks RJ, Jones DP, Cooke ED, et al. The effect of captopril on cutaneous blood flow in patients with primary Raynaud's phenomenon. British Journal of Dermatology 1987;117(6):751-8.

\section{van de Wal 1987 \{published data only\}}

van de Wal HJ, Wijn PF, van Lier HJ, Skotnicki SH. Quantitative study of the effects of Ketanserin in patients with primary Raynaud's phenomenon. A randomized, double blind, placebo controlled investigation and an additional long term open trial. Microcirculation, Endothelium and Lymphatics 1985;2(6):657-85.

* van de Wal HJ, Wijn PF, van Lier HJ, Skotnicki SH. The effectiveness of ketanserin in patients with primary Raynaud's phenomenon. A randomized, double blind, placebo controlled study. International Angiology 1987;6(3):313-22.
Vayssairat 1996 \{published data only\}

Vayssairat M. Controlled multicenter double blind trial of an oral analog of prostacyclin in the treatment of primary Raynaud's phenomenon. French Microcirculation Society Multicentre Group for the Study of Vascular Acrosyndromes. Journal of Rheumatology 1996;23(11):1917-20.

\section{References to studies excluded from this review}

\section{Arneklo-Nobin 1988 \{published data only\}}

Arneklo-Nobin B, Elmer O, Akesson A. Effect of long-term ketanserin treatment on 5-HT levels, platelet-aggregation and peripheral circulation in patients with Raynaud's phenomenon. A double-blind, placebo-controlled cross-over study. International Angiology 1988;7(1):19-25.

\section{Arnot 1978 \{published data only\}}

Arnot RS, Boroda C, Peacock JH. Pathophysiology of capillary circulation: Raynaud's disease. Angiology 1978;29(1):48-52.

\section{Arosio 1989 \{published data only\}}

Arosio E, Montesi G, Zannoni M, Paluani F, Lechi A. Comparative efficacy of ketanserin and pentoxiphylline in treatment of Raynaud's phenomenon. Angiology 1989;40(7):633-8.

\section{Arosio 1991 \{published data only\}}

Arosio E, Montesi G, Zannoni M, Perbellini L, Paluani F, Lechi A. Efficacy of ketanserin in the therapy of Raynaud's phenomenon: thermometric data. Angiology 1991;42(5):408-13.

Bali 2011 \{published data only\}

Bali G, Schwantzer G, Aberer F, Kraenke B, Aberer E, Bali G, et al. Discontinuing long-term Iloprost treatment for Raynaud's Phenomenon and systemic sclerosis: a singlecenter, randomized, placebo-controlled, double-blind study. Acta Dermatovenerologica Alpina, Panonica et Adriatica 2011;20(1):13-21.

Belch 1983 \{published data only\}

* Belch JJ, Cormie J, Newman P, McLaren M, Barbenel J, Capell $\mathrm{H}$, et al. Dazoxiben, a thromboxane synthetase inhibitor, in the treatment of Raynaud's syndrome: a double-blind trial. British Journal of Clinical Pharmacology 1983;15:113S-116S.

Belch JJF, Cormie J, Pinkerton L, Lowe GDO, Capell H, Forbes CD, et al. Evaluation of UK-37248: A thromboxane synthatase inhibitor, in the treatment of Raynaud's syndrome. Haemostasis. 12 1982; Vol. 12, issue Supplement 1:179-Abstract No 330.

\section{Belch 1995 \{published data only\}}

Belch JJ, Capell HA, Cooke ED, Kirby JD, Lau CS, Madhok R, Murphy E, Steinberg M. Oral iloprost as a treatment for Raynaud's syndrome: a double blind multicentre placebo controlled study. Annals of the Rheumatic Diseases 1995;54(3):197-200. 
Bounameaux 1986 \{published data only\}

Bounameaux HM, Hellemans $\mathrm{H}$, Verhaege R. Digital pressure and flow measurement upon local cooling in Raynaud's disease. Effect of naftidrofuryl. International Angiology 1986;5(1):39-44.

\section{Bredie 2012 \{published data only\}}

Bredie SJH, Jong MC. No significant effect of ginkgo biloba special extract EGb 761 in the treatment of primary raynaud phenomenon: a randomized controlled trial. Journal of Cardiovascular Pharmacology 2012;59(3):215-21.

\section{Bunker 1991 \{published data only\}}

Bunker CB, Foreman JC, Dowd PM. Digital cutaneous vascular responses to histamine and neuropeptides in Raynaud's phenomenon. The Journal of Investigative Dermatology 1991;96(3):314-7.

\section{Bunker 1993 \{published data only\}}

Bunker CB, Reavley C, O'Shaughnessy DJ, Dowd PM. Calcitonin gene-related peptide in treatment of severe peripheral vascular insufficiency in Raynaud's phenomenon. Lancet 1993;342(8863):80-3.

\section{Cabane 1985 \{published data only\}}

Cabane J, Boue F, Godeau P, Lecompte T, Charpentier MC, Samama M, et al. Trial treatment of severe Raynaud's phenomenon with prostacyclin (PGI2). [French] Trial treatment of severe Raynaud's phenomenon with prostacyclin (PG12). Revue de Medecine Interne 1985;6(5):581-9.

\section{Caglayan 2006 \{published data only\}}

Caglayan E, Huntgeburth M, Karasch T, Weihrauch J, Hunzelmann N, Krieg T, et al. Phosphodiesterase type 5 inhibition is a novel therapeutic option in Raynaud disease. Archives of Internal Medicine 2006;166(2):231-3.

\section{Caglayan 2011 \{published data only\}}

Caglayan E, Axmann S, Hellmich M, Moinzadeh P, Huntgeburth M, Hunzelmann N, et al. Vardenafil in patients with raynaud's syndrome. European Heart Journal 2011;32:655.

\section{Choi 2009 \{published data only\}}

Choi W-S, Choi C-J, Kim K-S, Lee J-H, Song C-H, Chung J-H, et al. To compare the efficacy and safety of nifedipine sustained release with Ginkgo biloba extract to treat patients with primary Raynaud's phenomenon in South Korea; Korean Raynaud study (KOARA study). Clinical Rheumatology 2009;28(5):553-9.

\section{Clement 1986 \{published data only\}}

Clement DL, Duprez D, De Pue N. Effect of indoramin on finger circulation in patients with Raynaud disease. Journal of Cardiovascular Pharmacology 1986;8(Suppl.2):S84-S87.

\section{Cleophas 1984 \{published data only\}}

Cleophas TJ, van Lier HJ, Faaber P, Fennis JF, van't Laar A. Therapeutic efficacy of alpha-adrenoceptor blockade in primary and secondary Raynaud's syndrome. Angiology 1984;35(11):719-23.
* Cleophas TJ, van Lier HJ, Fennis JF, van't Laar A. Treatment of Raynaud's syndrome with adrenergic alpha-blockade with or without beta-blockade. Angiology 1984;35(1):29-37.

\section{Codella 1989 \{published data only\}}

Codella O, Caramaschi P, Olivieri O, Perbellini L, Perbellini A, Bambara LM, et al. Controlled comparison of ketanserin and nifedipine in Raynaud's phenomenon. Angiology 1989;40(2):114-21.

Coffman 1989 \{published data only\}

Coffman JD, Clement DL, Creager MA, Dormandy JA Janssens MM, McKendry RJR, et al. International study of ketanserin in Raynaud's phenomenon. The American Journal of Medicine 1989;87(3):264-8.

Coleiro 2001 \{published data only\}

Coleiro B, Marshall SE, Denton CP, Howell K, Blann A, Welsh KI, et al. Treatment of Raynaud's phenomenon with the selective serotonin reuptake inhibitor fluoxetine. Rheumatology 2001;40(9):1038-43.

\section{Courbier 1981 \{published data only\}}

Courbier R, Bergeron P, Fouque R. Double-blind capillaroscopic study of the activity of buflomedil in Raynaud's syndrome: a report on 80 cases. Angiology 1981;32(10):676-8.

\section{Csiki 2011 \{published data only\}}

Csiki Z, Garai I, Shemirani AH, Papp G, Zsori KS, Andras C, et al. The effect of metoprolol alone and combined metoprololfelodipin on the digital microcirculation of patients with primary Raynaud's syndrome. Microvascular Research 2011;82(1):84-7.

\section{Davinroy 1993 \{published data only\}}

Davinroy M, Mosnier M. Double-blind clinical evaluation of naftidrofuryl in Raynaud's phenomenon. Semaine des Hopitaux 1993;69(36):1322-6.

\section{Dompeling 1992 \{published data only\}}

Dompeling EC, Smit AJ. Assessment of pinacidil in patients with primary Raynaud's phenomenon. Vasa-Supplementum 1992;34:34-7.

\section{Dormandy 1988 \{published data only\}}

Dormandy JA, Berent A, Downes SJ. The use of the selective serotonin S2 receptor antagonist Ketanserin in the treatment of Raynaud's phenomenon. European Journal of Vascular Surgery 1988;2(6):371-5.

Dowie 1990 \{published data only\}

Dowie A, Francis JL, Roath OS, Challenor VF, Waller DG. Platelet aggregation in primary Raynaud's phenomenon and the effect of enalapril administration. Platelets 1990;1(1):25-7.

\section{Drury 1985 \{published data only\}}

Drury JK, Belch JJ, McGregor M, Forbes CD. The effect of a prostacyclin analogue (Iloprost) on skin temperature. Prostaglandins Leukotrienes and Medicine 1985;19(3):301-3. 
Dumoulin 1981 \{published data only\}

Dumoulin J. Trial of a new drug in Raynaud's disease. Clinical and thermographic control. Electrodiagnostic Therapie 1981;18(4):168-174.

\section{Dziadzio 1999 \{published data only\}}

Dziadzio M, Denton CP, Smith R, Howell K, Blann A, Bowers E, et al. Losartan therapy for Raynaud's phenomenon and scleroderma: clinical and biochemical findings in a fifteenweek, randomized, parallel-group, controlled trial. Arthritis and Rheumatism 1999;42(12):2646-55.

\section{Friedman 2007 \{published data only\}}

Friedman EA, Harris PA, Wood AJ, Stein CM, Kurnik D. The effects of tadalafil on cold-induced vasoconstriction in patients with Raynaud's phenomenon. Clinical Pharmacology and Therapeutics 2007;81(4):503-9.

\section{Fries 2005 \{published data only\}}

Fries R, Shariat K, von Wilmowsky H, Bohm M. Sildenafil in the treatment of Raynaud's phenomenon resistant to vasodilatory therapy [see comment]. Circulation 2005;112(19):2980-5.

\section{Gresele 1992 \{published data only\}}

Gresele P, Volpato R, Migliacci R, Vezza R, Boschetti E, Nenci GG. Thromboxane does not play a significant role in acute, cold-induced vasoconstriction in Raynaud's phenomenon. Studies with combined thromboxane synthase inhibition and thromboxane receptor antagonism. Thrombosis Research 1992;66(2-3):259-64.

\section{Grigg 1989 \{published data only\}}

Grigg MJ, Nicolaides AN, Papadakis K, Wolfe JH. The efficacy of thymoxamine in primary Raynaud's phenomenon. European Journal of Vascular Surgery 1989;3(4):309-13.

\section{Hentzer 1966 \{published data only\}}

Hentzer E. Treatment of peripheral arterial insufficiency with inositol nicotinate (Hexanit) [Behandling af perifer arteriel insufficiens med inositoli nicotinase (Hexanit)]. Nordisk Medicin 1966;76(38):1090-3.

\section{Hiida 1996 \{published data only\}}

Hiida M, Ushiyama O, Suzuki N, Ohta A, Nagasawa K, Yamaguchi M. The effect of beraprost sodium on the Raynaud's phenomenon. Nihon Rinsho Meneki Gakkai Kaishi 1996;19(3):193-200.

\section{Holti 1979 \{published data only\}}

Holti G. An experimentally controlled evaluation of the effect of inositol nicotinate upon the digital blood flow in patients with Raynaud's phenomenon. Journal of International Medical Research 1979;7(6):473-83.

\section{Janini 1988 \{published data only\}}

Janini SD, Scott DG, Coppock JS, Bacon PA, Kendall MJ. Enalapril in Raynaud's phenomenon. Journal of Clincal Pharmacy and Therapeutics 1988;13(2):145-50.
Jones 1983 \{published data only\}

Jones EW, Hawkey CJ. A thromboxane synthetase inhibitor in Raynaud's phenomenon. Prostaglandins Leukotrienes and Medicine 1983;12(1):67-71.

\section{Kahan 1985 \{published data only\}}

Kahan A, Foult JM, Weber S, Amor B, Menkes CJ, Degeorges M. Nifedipine and alpha 1-adrenergic blockade in Raynaud's phenomenon. European Heart Journal 1985;6(8):702-5.

Kyle 1992 \{published data only\}

Kyle MV, Belcher G, Hazleman BL. Placebo controlled study showing therapeutic benefit of iloprost in the treatment of Raynaud's phenomenon. Journal of Rheumatology 1992;19(9):1403-6.

\section{Longstaff 1985 \{published data only\}}

Longstaff J, Gush R, Williams EH, Jayson MI. Effects of ketanserin on peripheral blood flow, haemorheology, and platelet function in patients with Raynaud's phenomenon. Journal of Cardiovascular Pharmacology 1985;7(Suppl.7):S99-101.

\section{Luderer 1984 \{published data only\}}

Luderer JR, Nicholas GG, Neumyer MM, Riley DL, Vary JE, Garcia G, et al. Dazoxiben, a thromboxane synthetase inhibitor, in Raynaud's phenomenon. Clinical Pharmacology and Therapeutics 1984;36(1):105-15.

Malenfant 2011 \{published data only\} Malenfant D, Summers K, Seney S, McBain D, Petrlich L, Watson S, et al. Results of a pilot randomized placebocontrolled trial in primary and secondary Raynaud's Phenomenon with St. John's Wort: Detecting changes in angiogenic cytokines when RP improves. ISRN Rheumatology 2011:Article ID 580704.

\section{Marasini 1988 \{published data only\}}

Marasini B, Biondi ML, Bianchi E, Dell'Orto P, Agostoni A. Ketanserin treatment and serotonin in patients with primary and secondary Raynaud's phenomenon. European Journal of Clinical Pharmacology 1988;35(4):419-21.

\section{Marasini 2004 \{published data only\}}

Marasini B, Massarotti M, Bottasso B, Coppola R, Papa ND, Maglione W, et al. Comparison between iloprost and alprostadil in the treatment of Raynaud's phenomenon. Scandinavian Journal of Rheumatology 2004;33(4):253-6.

\section{Maurel 1995 \{published data only\}}

Maurel A, Betrancourt JC, van Frenkel R, Thuillez C. Action of Buflomedil on the cutaneous microcirculation studied by a Cold provocation test. Multicentre double-blind placebo controlled trial. Journal des Maladies Vasculaires 1995;20(2):127-33.

\section{Meloni 1987 \{published data only\}}

Meloni F, Transi MG, Sciacca V, De Felice C, Bagarone A, Sciacca A. Therapeutic efficacy of ketanserin, a selective antagonist of the serotonin (5-HT2) receptors, in primary and secondary Raynaud's phenomenon. Angiology 1987;38(7):530-6. 
Mohrland 1985 \{published data only\}

Mohrland JS, Porter JM, Smith EA, Belch J, Simms MH. A multiclinic, placebo-controlled, double-blind study of prostaglandin E1 in Raynaud's syndrome. Annals of the Rheumatic Diseases 1985;44(11):754-60.

\section{Murphy 1985 \{published data only\}}

Murphy R. The effect of inositol nicotinate (Hexopal) in patients with Raynaud's phenomenon. A placebo-controlled study. Clinical Trials Journal 1985;22(6):521-9.

\section{NCT00048763 \{published data only\}}

NCT00048763. Safety and efficacy of pletal (cilostazol) for the treatment of juvenile primary and secondary Raynaud's phenomenon. http://clinicaltrials.gov/ct2/show/NCT00048763? term=nct00048763\&rank=1 (accessed 14.03.2012).

\section{NCT00048776 \{published data only\}}

NCT00048776. Safety and efficacy of pletal (cilostazol) for the treatment of juvenile primary and secondary Raynaud's phenomenon. http://clinicaltrials.gov/ct2/show/NCT00048776? term=nct00048776\&rank=1 (accessed 14.03.2012).

\section{NCT01233999 \{published data only\}}

NCT01233999. Botulinum toxin in the treatment of Raynaud's. http://clinicaltrials.gov/ct2/show/NCT01233999? term=nct01233999\&rank=1 (accessed 14.3.2012).

\section{Nielsen 1983 \{published data only\}}

Nielsen SL, Vitting K, Rasmussen K. Prazosin treatment of primary Raynaud's phenomenon. European Journal of Clinical Pharmacology 1983;24(3):421-3.

\section{Nilsen 1979 \{published data only\}}

Nilsen KH. Effects of naftidrofuryl on microcirculatory cold sensitivity in Raynaud's phenomenon. British Medical Journal 1979;1(6155):20-1.

\section{Pancera 1997 \{published data only\}}

Pancera P, Sansone S, Secchi S, Covi G, Lechi A. The effects of thromboxane $\mathrm{A} 2$ inhibition (picotamide) and angiotensin II receptor blockade (losartan) in primary Raynaud's phenomenon. Journal of Internal Medicine 1997;242(5):373-6.

\section{Paterna 1997 \{published data only\}}

Paterna S, Pinto A, Arrostuto A, Cannavo MG, Di Pasquale P, Cottone $\mathrm{C}$, et al. Raynaud's phenomenon: effects of terazosin. Minerva Cardioangiologica 1997;45(5):215-21.

\section{Pola 1993 \{published data only\}}

Pola P, Tondi P, Serricchio M, Favuzzi A, Gerardino L. New prospects for the treatment of Raynaud's phenomenon using a serotoninergic S2 receptor antagonist (ketanserin) and stable derivatives of prostacyclin. Angiology 1993;44(2):123-8.

\section{Rajagopalan 2003 \{published data only\}}

Rajagopalan S, Pfenninger D, Somers E, Kehrer C, Chakrabarti A, Mukherjee D, et al. Effects of cilostazol in patients with Raynaud's syndrome. American Journal of Cardiology 2003;92(11):1310-5.

\section{Russell 1985 \{published data only\}}

Russell IJ, Lessard JA. Prazosin treatment of Raynaud's phenomenon: A double blind single crossover study. Journal of Rheumatology 1985;12(1):94-8.

\section{Rustin 1984 \{published data only\}}

Rustin MH, Grimes SM, Kovacs IB, Cooke ED, Bowcock SA, Sowemimo-Coker SO, et al. A double blind trial of UK-38,485, an orally active thromboxane synthetase inhibitor, in the treatment of Raynaud's syndrome. European Journal of Clinical Pharmacology 1984;27(1):61-5.

\section{Sandhagen 1984 \{published data only\}}

Sandhagen B, Wegener T, Hagg A. Blood viscosity, finger systolic pressure and effect of dazoxiben treatment in primary vasospastic disease. Upsala Journal of Medical Sciences 1984;89(3):213-9

\section{Seibold 1984 \{published data only\}}

Seibold JR, Jageneau AH. Treatment of Raynaud's phenomenon with ketanserin, a selective antagonist of the serotonin2 (5-HT2) receptor. Arthritis and Rheumatism 1984;27(2):139-46.

Seibold 1986 \{published data only\}

Seibold JR, Terregino CA. Selective antagonism of S2serotonergic receptors relieves but does not prevent cold induced vasoconstriction in primary Raynaud's phenomenon. Journal of Rheumatology 1986;13(2):337-40.

Shawket 1991 \{published data only\}

Shawket S, Dickerson C, Hazleman B, Brown MJ. Prolonged effect of CGRP in Raynaud's patients: a double-blind randomised comparison with prostacyclin. British Journal of Clinical Pharmacology 1991;32:209-13.

Shcherbakov 1992 \{published data only\} Shcherbakov AB, Muravyev Yu V, Sokolov VB, Khitraya EG, Guseva NG. Captopril therapy of Raynaud's syndrome. Revmatologiia 1992; Issue 1:14-16.

Shenoy 2010 \{published data only\} Shenoy PD, Kumar S, Jha LK, Choudhary SK, Singh U, Misra R, et al. Efficacy of tadalafil in secondary Raynaud's phenomenon resistant to vasodilator therapy: a double-blind randomized cross-over trial. Rheumatology 2010;49(12):2420-8.

\section{Sunderland 1988 \{published data only\}}

Sunderland GT, Belch JJ, Sturrock RD, Forbes CD, McKay AJ. A double blind randomised placebo controlled trial of hexopal in primary Raynaud's disease. Clinical Rheumatology 1988;7(1):46-9.

\section{Tindall 1985 \{published data only\}}

Tindall H, Tooke JE, Menys VC, Martin MF, Davies JA. Effect of dazoxiben, a thromboxane synthetase inhibitor on skinblood flow following cold challenge in patients with Raynaud's phenomenon. European Journal of Clinical Investigation 1985;15(1):20-3. 
Tooke 1990 \{published data only\}

Tooke JE, Williams SA, Rawlinson DW, Black C. Ketanserin and capillary flow in Raynaud's phenomenon. International Journal of Microcirculation-Clinical and Experimental 1990;9(3):249-55.

Tooke JE, Williams SA, Rawlinson DW, Black C. The effects of ketanserin on capillary flow in Raynaud's phenomenon. Clinical Science 1987; Vol. 17:74P.

\section{Torley 1990 \{published data only\}}

Torley HI, Madhok R, Capel H. A double blind randomised comparison of two doses of iloprost in the treatment of Raynauds phenomenon. Scottish Medical Journal 1990;35(5):157.

\section{Tosi 1987 \{published data only\}}

Tosi S, Marchesoni A, Messina K, Bellintani C, Sironi G, Faravelli C. Treatment of Raynaud's phenomenon with captopril. Drugs Under Experimental and Clinical Research 1987;13(1):37-42.

\section{Tucker 1999 \{published data only\}}

Tucker AT, Pearson RM, Cooke ED, Benjamin N. Effect of nitricoxide-generating system on microcirculatory blood flow in skin of patients with severe Raynaud's syndrome: a randomised trial. Lancet 1999;354(9191):1670-5.

\section{Wasir 1983 \{published data only\}}

Wasir HS, Singh G, Kaul R, Sachdeva U, Khan WA, Chhina GS, Prakash K, Malaviya AN. A comparative study of trifluoperazine a calmodulin inhibitor, nifedipine, dipyridamole and intraarterial reserpine in the treatment of raynaud's phenomenon: a double blind randomised controlled trial. Indian Heart Journal 1983;35(5):306.

\section{Wesseling 1981 \{published data only\}}

Wesseling H, den Heeten A, Wouda AA. Sublingual and oral isoxsuprine in patients with Raynaud's phenomenon. European Journal of Clinical Pharmacology 1981;20(5):329-33.

Wise 1994 \{published data only\}

Wise RA, Wigley F. Acute effects of misoprostol on digital circulation in patients with Raynaud's phenomenon. Journal of Rheumatology 1994;21(1):80-3.

\section{Wollersheim 1986 \{published data only\}}

Wollersheim $\mathrm{H}$, Thien T, Fennis J, van Elteren $\mathrm{P}$, van't Laar A. Double-blind, placebo-controlled study of prazosin in Raynaud's phenomenon. Clinical Pharmacology and Therapeutics 1986;40(2):219-25.

\section{Wollersheim 1988 \{published data only\}}

Wollersheim $\mathrm{H}$, Thien T. Dose-response study of prazosin in Raynaud's phenomenon: clinical effectiveness versus sideeffects. Journal of Clinical Pharmacology 1988;28(12):1089-93.

\section{References to ongoing studies}

NCT01090492 \{published data only\}

NCT01090492. PF-00489791 for the treatment of Raynaud's. http://clinicaltrials.gov/ct2/show/NCT01090492? term=raynaud\&rank=1 (accessed 15 May 2012).

\section{Additional references}

\section{ATC classification}

ATC 2007. Anatomical Therapeutical Chemical Classification, WHO. http://www.whocc.no/atcddd (accessed 26.04.2007).

\section{Block 2001}

Block JA, Sequeira W. Raynaud's phenomenon. Lancet 2001;357(9273):2042-8.

\section{BNF53}

British National Formulary. BNF53. http://www.bnf.org/bnf/. British Medical Association and Royal Pharmaceutical Society of Great Britain: 2007, (accessed 25.04.2007).

\section{Campbell 1999}

Campbell MJ, Machin D. Medical statistics: A commonsense approach. 3rd Edition. Chichester: John Wiley \& Sons, Ltd., 1999. [ISBN-10: 0-471-98721-2 (pbk)]

\section{DerSimonian 1986}

DerSimonian R, Laird N. Meta-analysis in clinical trials. Controlled Clinical Trials 1986;7(3):177-88.

\section{Distler 2006}

Distler M, Distler J, Ciurea A, Kyburz D, Muller-Ladner U, Reich K, et al. [Evidence-based therapy of Raynaud's syndrome [Evidenzbasierte therapie des Raynaud-syndroms]. Zeitschrift fur Rheumatologie 2006;65(4):285-9.

\section{Elbourne 2002}

Elbourne DR, Altman DG, Higgins JP, Curtin F, Worthington HV, Vail A. Meta-analyses involving cross-over trials: methodological issues. International Journal of Epidemiology 2002;31(1):140-9.

\section{Farrar 2000}

Farrar JT, Portenoy RK, Berlin JA, Kinman JL, Strom BL. Defining the clinically important difference in pain outcome measures. Pain 2000;88(3):287-94.

\section{Herrick 2008}

Herrick AL. Calcium channel blockers for primary Raynaud's Phenomenon (Protocol). Cochrane Database of Systematic Reviews 2008, Issue 3. [DOI: 10.1002/14651858.CD002069.pub3]

\section{Higgins 2006}

Higgins JPT, Green S, editors. Cochrane Handbook for Systematic Reviews of Interventions 4.2.6 (Updated September 2006). www.cochrane.org/resources/handbook/hbook.htm (accessed 10th January 2007).

\section{Hirschl 2006}

Hirschl M, Hirschl K, Lenz M, Katzenschlager R, Hutter HP, Kundi M. Transition from primary Raynaud's phenomenon to 
secondary Raynaud's phenomenon identified by diagnosis of an associated disease: results of ten years of prospective surveillance. Arthritis and Rheumatism 2006;54(6):1974-81.

\section{Ho 1998}

Ho ML, Belch JJF. Raynaud's phenomenon: State of the Art 1998. Scandinavian Journal of Rheumatology 1998;27(5):319-22.

\section{Jadad 1996}

Jadad AR, Moore RA, Carroll D, Jenkinson C, Reynolds DJM, Gavaghan DJ, et al. Assessing the quality of reports of randomized clinical trials: Is blinding necessary?. Controlled Clinical Trials 1996;17(1):1-12.

\section{Lexchin 2003}

Lexchin J, Bero LA, Djulbegovic B, Clark O. Pharmaceutical industry sponsorship and research outcome and quality: systematic review. British Medical Journal 2003;326(7400):1167-70.

\section{Medicines.org.uk}

Medicines.org.uk. electronic Medicines Compendium (eMC). www.medicines.org.uk (accessed 24.04.2007).

\section{Merkel 2002}

Merkel PA, Herlyn K, Martin RW, Anderson JJ, Mayes MD, Bells $P$, et al. Measuring disease activity and functional status in patients with scleroderma and Raynaud's phenomenon. Arthritis and Rheumatism 2002;46(9):2410-20.

\section{Moher 2001}

Moher D, Schulz KF, Altman D. The CONSORT statement: Revised recommendations for improving the quality of reports of parallel-group randomized trials. JAMA-Journal of the American Medical Association 2001;285(15):1987-91.

\section{Pope 2006}

Pope J. Raynaud's Phenomenon (primary). http:// www.clinicalevidence.com/ceweb/conditions/ cvd/1119/1119.jsp (accessed 26.04.2007).

\section{Prodigy 2006}

Prodigy Guidance. Raynaud's phenomenon. http:// www.cks.library.nhs.uk/raynauds_phenomenon. National Library for Health. Clinical Knowledge Summaries, last revision May 2006, (accessed 19.04.2007).

\section{Schulz 1995}

Schulz KF, Chalmers I, Hayes RJ, Altman DG. Empirical evidence of bias. Dimensions of methodological quality associated with estimates of treatment effects in controlled trials. JAMA 1995;273(5):408-12.

\section{Silman 1990}

Silman A, Holligan S, Brennan P, Maddison P. Prevalence of symptoms of Raynaud's phenomenon in general practice. British Medical Journal 1990;301(6752):590-2.

\section{Spencer-Green 1998}

Spencer-Green G. Outcomes in primary Raynaud phenomenon: a meta-analysis of the frequency, rates, and predictors of transition to secondary diseases. Archives of Internal Medicine 1998;158(6):595-600.

\section{Thompson 2005}

Thompson AE, Pope JE. Calcium channel blockers for primary Raynaud's phenomenon: a meta-analysis. Rheumatology 2005;44(2):145-50.

\section{Wigley 2002}

Wigley FM. Clinical practice. Raynaud's phenomenon. New England Journal of Medicine 2002;347(13):1001-8.

\section{References to other published versions of this review Vinjar 2008}

Vinjar B, Stewart M. Oral vasodilators for primary Raynaud's phenomenon. Cochrane Database of Systematic Reviews 2008, Issue 2. [DOI: 10.1002/14651858.CD006687.pub2]

* Indicates the major publication for the study

\section{CHARACTERISTICS OF STUDIES}

Characteristics of included studies [ordered by study ID]

\section{Challenor 1991}

Methods Study design: Randomised, double-blind, placebo controlled, cross-over trial. Method of randomisation: Not stated.

Concealment of allocation: Not stated. Exclusions post randomisation: 1 . Losses to follow up: None.

$\begin{array}{ll}\text { Participants } & \text { Country: UK. } \\ \text { Setting: Not stated, winter season. } \\ \text { No.: } 21 / 21 \text { primary RP. } \\ \text { Age: Mean } 38.6 \text { years (range } 21 \text { to } 59 \text { years). } \\ \text { Sex: Females } 19 ; \text { males } 2 . \\ \text { Other: } 14 \% \text { smokers. }\end{array}$


Challenor 1991 (Continued)

Inclusion criteria: Primary RP.

Exclusion criteria: Secondary RP (history, examination and appropriate blood tests).

\begin{tabular}{ll}
\hline Interventions & Treatment: Enalapril 20 mg once daily. \\
& Control: Matching placebo. \\
& Duration: $2 \times 4$ weeks (including 3-day dose titration 1st week). \\
& Wash-out period: None.
\end{tabular}

Outcomes
2. Frequency of attacks.
3. Severity of attacks (1: mild, 2: moderate, 3: severe).
4. Subjective assessment of improvement: 5 -point rating scale and $10 \mathrm{~cm}$ VAS scale.
5. Skin temperature at rest and after cold challenge: cooled water bath 15 degrees 5 minutes.
6. Adverse events.
7. Enalapril at concentrations 2 and 4 hours after last dose.

\begin{tabular}{ll}
\hline Notes & No power calculation; Jadad score $=3$. \\
& Support: Pharmaceutical company
\end{tabular}

\section{Risk of bias}

\begin{tabular}{lll}
\hline Bias & Authors' judgement & Support for judgement \\
\hline $\begin{array}{l}\text { Allocation concealment } \\
\text { (selection bias) }\end{array}$ & Unclear risk & B - Unclear \\
\hline
\end{tabular}

Ettinger 1984

\begin{tabular}{ll}
\hline Methods & Study design: Randomised, double-blind, placebo controlled, cross-over trial. \\
& Method of randomisation: "Randomly assigned". \\
& Concealment of allocation: Not stated. \\
& Exclusions post randomisation: 1 inadequate compliance (in primary RP group). \\
Losses to follow up: None (in primary RP group). & \\
Country: USA \\
Setting: Hospital, winter season. \\
No.: $6 / 25$ primary RP. \\
Age: Mean 33.8 years (range 22 to 55 years). \\
Sex: Females 5; males 1. \\
Inclusion criteria: Primary or Secondary RP. At least 1 attack per day. Age $>18$ and $<65$ years. \\
Exclusion criteria: Serious renal, cardiac, hepatic, pulmonary, haematologic or metabolic disease. Con- \\
comitant treatment with aspirin, NSAIDS, dipyridamole, sulphinpyrazone, vasodilators, or drugs that \\
interfere with sympathetic nervous system function.
\end{tabular}

Interventions

Treatment: Dazoxiben $100 \mathrm{mg}$ four times daily or nifedipine $20 \mathrm{mg}$ three times daily.

Control: Placebo same doses, all took 7 capsules a day, drugs + placebo.

Duration: 10 weeks: 2 weeks placebo run-in period, $3 \times 2$ weeks of one of six possible sequences of three combinations of placebo, dazoxiben and nifedipine.

Wash-out: 1 week in between 2 week periods.

\begin{tabular}{ll}
\hline Outcomes & $\begin{array}{l}\text { 1. Frequency of attacks. } \\
\text { No subgroup data for other outcomes. }\end{array}$ \\
\hline Notes & $\begin{array}{l}\text { No power calculation; Jadad score }=3 . \\
\text { Support: Pharmaceutical company. } \\
\text { Dazoxiben: Experimental drug, unregistered. }\end{array}$
\end{tabular}




\section{Risk of bias}

\begin{tabular}{lll}
\hline Bias & Authors' judgement & Support for judgement \\
\hline $\begin{array}{l}\text { Allocation concealment } \\
\text { (selection bias) }\end{array}$ & Unclear risk & B - Unclear \\
\hline
\end{tabular}

\section{Jaffe 1980}

Study design: Randomised, double-blind, placebo controlled, cross-over trial.
Method of randomisation: "Random procedure".
Concealment of allocation: Not stated.
Exclusions post randomisation: 2 excluded because of no attacks in trial period (1 moxisylyte, 1 place-
bo).
Losses to follow up: Total 8 (19\%) lost to follow up for frequency data. Accessible data for 25 versus 26
participants ( $37 \%$ lost to follow up) for severity and duration of attacks data.

Participants
Setting: General practice, multicentre, winter season.
No.: $41 / 41$ primary RP (+33 chilblains, separate description and results).
Age: Median 41 years (range 17 to 73 years).
Sex: Females 27 ; males 14.
Other: $34 \%$ smokers.
Inclusion criteria: Primary RP.
Exclusion criteria: Age $<18$ or $>75$ years, recent myocardial infarction, angina pectoris, diabetes, hy-
pertension requiring drug treatment, pregnancy, tricyclic antidepressant medication, vasodilator ther-
apy within 2 weeks of admission to trial.

\begin{tabular}{|c|c|}
\hline Interventions & $\begin{array}{l}\text { Treatment: Thymoxamine (Moxisylyte) } 40 \mathrm{mg} \text { four times daily. } \\
\text { Control: Matching placebo } 1 \text { four times daily. } \\
\text { Duration: } 2 \times 2 \text { weeks. } \\
\text { Wash-out period: None. }\end{array}$ \\
\hline Outcomes & $\begin{array}{l}\text { 1. Frequency of attacks. } \\
\text { 2. Duration of attacks. } \\
\text { 3. Severity of attacks on 3-point scale (1: slight, 2: moderate, 3: severe). } \\
\text { 4. Severity score = frequency x severity grade. } \\
\text { 5. Adverse events. }\end{array}$ \\
\hline
\end{tabular}

\begin{tabular}{ll}
\hline Notes & No power calculation; Jadad score $=3$. \\
& Support: Not stated.
\end{tabular}

\section{Risk of bias}

\begin{tabular}{lll}
\hline Bias & Authors' judgement & Support for judgement \\
\hline $\begin{array}{l}\text { Allocation concealment } \\
\text { (selection bias) }\end{array}$ & Unclear risk & B - Unclear \\
\hline
\end{tabular}


Method of randomisation: Randomisation table.

Concealment of allocation: Distribution by randomisation table undertaken by manufacturer of strictly identical treatment packs. Code broken at end of trial.

Exclusions post randomisation: None.

Losses to follow up: None.

\begin{tabular}{|c|c|c|}
\hline Participants & \multicolumn{2}{|c|}{$\begin{array}{l}\text { Country: France. } \\
\text { Setting: Specialist outpatient clinic, } 2 \text { autumn and winter seasons. } \\
\text { No.: } 31 / 31 \text { primary RP. } \\
\text { Age: Mean } 39.3 \text { years (range } 22 \text { to } 67 \text { years). } \\
\text { Sex: Females } 28 ; \text { males } 3 \text {. } \\
\text { Other: } 27 \% \text { smokers. Concomitant disease: } 2 \text { diabetes, } 2 \text { arterial disease. } \\
\text { Inclusion criteria: Severe idiopathic RP, at least } 1 \text { attack related to cold exposure per day within the } \\
\text { past } 2 \text { years, according to clinical examination, blood tests and bilateral nailfold capillaroscopy. } \\
\text { Exclusion criteria: Unilateral RP secondary to thoracic outlet or locoregional pathologic disturbances. } \\
\text { Bilateral cases secondary to collagen disease or scleroderma. Patients treated with a vasoactive or } \\
\text { platelet aggregant drug less than } 2 \text { weeks prior to trial, pregnant or breast-feeding women. }\end{array}$} \\
\hline Interventions & \multicolumn{2}{|c|}{$\begin{array}{l}\text { Treatment: Buflomedil } 300 \text { mg twice daily. } \\
\text { Control: Placebo identical. } \\
\text { Duration: } 6 \text { months. }\end{array}$} \\
\hline Outcomes & \multicolumn{2}{|c|}{$\begin{array}{l}\text { 1. Mean number of attacks per day. } \\
\text { 2. Severity of attacks ( } 4 \text { point score: } 0 \text { : none, } 1 \text { : slight, } 2 \text { : moderate, } 3 \text { : severe). } \\
\text { 3. Adverse events. } \\
\text { 4. Efficacy confirmed by capillaroscopic criteria. }\end{array}$} \\
\hline Notes & \multicolumn{2}{|c|}{$\begin{array}{l}\text { No power calculation; Jadad score }=5 \text {. } \\
\text { Support: Not stated. }\end{array}$} \\
\hline \multicolumn{3}{|l|}{ Risk of bias } \\
\hline Bias & Authors' judgement & Support for judgement \\
\hline $\begin{array}{l}\text { Allocation concealment } \\
\text { (selection bias) }\end{array}$ & Low risk & A - Adequate \\
\hline
\end{tabular}

Madsen 1984

Methods Study design: Randomised, double-blind, placebo controlled, cross-over trial.

Method of randomisation: Not stated.

Concealment of allocation: Not stated.

Exclusions post randomisation: None.

Losses to follow up: None.

\begin{tabular}{ll}
\hline Participants & Country: Denmark. \\
& Setting: Not stated, winter season. \\
No.: $10 / 10$ primary RP. \\
Age: Median 44 years (range 27 to 71 years). \\
Sex: Females 8 ; males 2. \\
Inclusion criteria: Primary RP screened for under \\
Exclusion criteria: Secondary RP according to \\
Treatment: Captopril 25 mg three times daily. \\
Control: Placebo 1 three times daily. \\
Duration: $2 \times 6$ weeks.
\end{tabular}


Madsen 1984 (Continued)

Wash-out period: None.

Outcomes
2. Accompanying numbness or pain.
3. Improvement on 3-point scale: improved, unchanged, worse.
4. Adverse events.

Notes

No power calculation.

Jadad score $=3$.

Support: Pharmaceutical company.

\section{Risk of bias}

\begin{tabular}{lll}
\hline Bias & Authors' judgement & Support for judgement \\
\hline $\begin{array}{l}\text { Allocation concealment } \\
\text { (selection bias) }\end{array}$ & Unclear risk & B - Unclear \\
\hline
\end{tabular}

\section{Rustin 1987}

$\begin{array}{ll}\text { Methods } & \text { Study design: Randomised, double-blind, placebo controlled, cross-over trial. } \\ & \text { Method of randomisation: "Random number system". } \\ & \text { Concealment of allocation: Not stated. } \\ & \text { Exclusions post randomisation: } 1 \text { - pregnant. } \\ & \text { Losses to follow up: None for subjective data, } 1 \text { for objective data. }\end{array}$

Country: UK.
Setting: Specialist outpatient clinic, winter season.
No.: $15 / 15$ primary RP.
Age: Mean 35 years (range 21 to 52 years).
Sex: Females 15, males 0.
Other: $26 \%$ smokers.
Inclusion criteria: Primary RP according to diagnostic criteria with negative ANA, chest and hand radi-
ographs, lung function tests and nailfold capillaroscopy. No features of connective tissue disease on
general examination or occupational cause for RP.
Exclusion criteria: Hypertension, ischaemic heart disease, abnormal full blood count, impaired renal or
hepatic function.

Interventions Treatment: Captopril $25 \mathrm{mg}$ three times daily.

Control: Placebo three times daily.

Duration: 2 week placebo run-in, 2 x 6 weeks intervention.

Wash-out period: None.

Outcomes
2. Frequency of attacks.
3. Severity of attacks (mild, moderate, severe).
4. Pain of attacks (no scale).
5. Cold test 1 minute 20 degrees.
6. Digital blood flow by laser doppler flowmetry and photoplethysmography.
7. Adverse effects.

\begin{tabular}{ll}
\hline Notes & No power calculation. \\
& Jadad score $=3$. \\
& Support: Pharmaceutical company.
\end{tabular}

\section{Risk of bias}


Rustin 1987 (Continued)

\begin{tabular}{lll} 
Bias & Authors' judgement & Support for judgement \\
\hline $\begin{array}{l}\text { Allocation concealment } \\
\text { (selection bias) }\end{array}$ & Unclear risk & B - Unclear \\
\hline
\end{tabular}

van de Wal 1987

\begin{tabular}{ll}
\hline Methods & Study design: Randomised, double-blind, placebo controlled, cross-over trial. \\
& Method of randomisation: "Assigned at random". \\
Concealment of allocation: Not stated. \\
Exclusions post randomisation: None. \\
Losses to follow up: 1.
\end{tabular}

Treatment : Ketanserin $40 \mathrm{mg}$ twice daily (20 mg twice daily first two weeks).
Control: Placebo.
Duration: 4 weeks run-in with placebo, 2 × 6 weeks intervention.
Wash-out period: None.

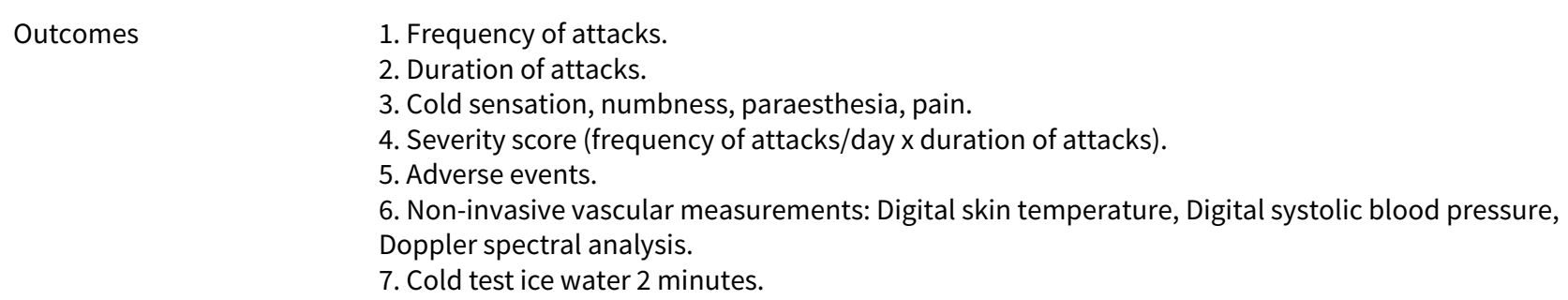

\section{Risk of bias}

\begin{tabular}{lll}
\hline Bias & Authors' judgement & Support for judgement \\
\hline $\begin{array}{l}\text { Allocation concealment } \\
\text { (selection bias) }\end{array}$ & Unclear risk & B - Unclear \\
\hline
\end{tabular}

\section{Vayssairat 1996}


Method of randomisation: Random number table prepared by the pharmaceutical company, individual randomisation envelopes left in each centre.

Concealment of allocation: Centres unaware of randomisation code.

Exclusions post randomisation: None (7 pre-randomisation).

Losses to follow up: 16 (9 in beraprost group, 7 in placebo group).

Country: France.
Setting: Multicentre, specialist outpatient clinic.
No.: $125 / 125$ primary RP (118 after randomisation).
Age: (Mean \pm SD) Beraprost group $40 \pm 12$ years, placebo group $37 \pm 11$ years.
Sex: females $96 ;$ males 29 .
Inclusion criteria: Primary RP defined by criteria: Duration $>2$ years, no underlying disease, no past or
present digital tip necrosis, with normal pulses, normal nailfold capillary microscopy, no positive ANA.
Exclusion criteria: Age $<18$ or $>65$ years, pregnancy, secondary RP, $<5$ attacks of RP per week, associ-
ated acute or chronic disease, any drug treatment except paracetamol and contraceptive pills.

Interventions Treatment: Phase II: Beraprost sodium $20 \mu \mathrm{g}$ three times daily; Phase III: Beraprost sodium $40 \mu \mathrm{g}$ three times daily.

Control: Placebo.

Duration: Phase I: 2 weeks run-in no treatment; Phase II: 3 weeks; Phase III: 3 weeks.

\begin{tabular}{ll}
\hline Outcomes & 1. Number of attacks. \\
2. Severity of attacks (graded 1 to 4). \\
3. Overall disability VAS scale $100 \mathrm{~mm}$. \\
4. Adverse events. \\
5. Cold test (13 degrees, 5 mins) and haemodynamic data. \\
6. Blood tests.
\end{tabular}

Notes

Includes sample size calculation.

Jadad score $=5$.

Support: Pharmaceutical company.

\section{Risk of bias}

\begin{tabular}{lll}
\hline Bias & Authors' judgement & Support for judgement \\
\hline $\begin{array}{l}\text { Allocation concealment } \\
\text { (selection bias) }\end{array}$ & Low risk & A - Adequate \\
\hline
\end{tabular}

RP: Raynaud's phenomenon.

BP: Blood pressure

VAS: Visual analogue scale.

ANA: Antinuclear antibodies

NSAIDS: Non-steroidal anti-inflammatory drugs

Characteristics of excluded studies [ordered by study ID]

\begin{tabular}{ll}
\hline Study & Reason for exclusion \\
\hline Arneklo-Nobin 1988 & Data not presented per subgroup, unable to include statistical data. \\
\hline Arnot 1978 & $\begin{array}{l}\text { No outcomes for frequency/severity of attacks. The evaluated outcomes are not among those eval- } \\
\text { uated in this review. }\end{array}$ \\
\hline Arosio 1989 & Results presented combined for all participants, no subgroup analysis possible. \\
\hline Arosio 1991 & No control group, not a randomised controlled trial.
\end{tabular}




\begin{tabular}{|c|c|}
\hline Study & Reason for exclusion \\
\hline Bali 2011 & $\begin{array}{l}\text { Intravenous treatment. Mixture of primary and secondary RP, results presented combined for all } \\
\text { participants. }\end{array}$ \\
\hline Belch 1983 & Results presented combined for all participants, no subgroup analysis possible. \\
\hline Belch 1995 & All participants secondary RP. \\
\hline Bounameaux 1986 & Not a randomised controlled trial. \\
\hline Bredie 2012 & Not vasodilator. \\
\hline Bunker 1991 & Intradermal injections. \\
\hline Bunker 1993 & All participants secondary RP, intravenous treatment. \\
\hline Cabane 1985 & Intravenous treatment. \\
\hline Caglayan 2006 & Open study, not a randomised controlled trial. \\
\hline Caglayan 2011 & Not RCT, no separate data available for primary RP. \\
\hline Choi 2009 & Calcium-channel blocker. \\
\hline Clement 1986 & Participants do not meet inclusion criteria. \\
\hline Cleophas 1984 & $\begin{array}{l}\text { Some participants described as primary RP are secondary RP according to current diagnostic crit } \\
\text { ria. }\end{array}$ \\
\hline
\end{tabular}

\begin{tabular}{ll}
\hline Codella 1989 & No data for participants with primary RP can be identified, no subgroup analysis possible. \\
\hline Coffman 1989 & Results presented combined for all participants, no subgroup analysis possible. \\
\hline
\end{tabular}

\begin{tabular}{ll}
\hline Coleiro 2001 & Results presented combined for all participants, no subgroup analysis possible. \\
\hline Courbier 1981 & Single dose, intravenous treatment. \\
\hline Csiki 2011 & Beta-blocker compared with calcium channel blocker.
\end{tabular}

\begin{tabular}{ll}
\hline Davinroy 1993 & Results presented combined for all participants, no subgroup analysis possible. \\
\hline Dompeling 1992 & Single dose trial, comparison with calcium channel blocker. \\
\hline Dormandy 1988 & $\begin{array}{l}\text { Data not presented per subgroup, no frequency/severity of attacks outcomes. The evaluated out- } \\
\text { comes are not among those evaluated in this review. }\end{array}$
\end{tabular}

\begin{tabular}{ll}
\hline Dowie 1990 & $\begin{array}{l}\text { No results for frequency/severity of attacks. The evaluated outcomes are not among those evaluat- } \\
\text { ed in this review. }\end{array}$ \\
\hline Drury 1985 & Transdermal treatment, participants do not meet inclusion criteria. \\
\hline Dumoulin 1981 & Results presented combined for all participants, no subgroup analysis possible. \\
\hline Dziadzio 1999 & Parallel design study, comparison with calcium channel blocker. Unblinded study. \\
\hline Friedman 2007 & Single dose study, no outcomes for frequency/severity of attacks. \\
\hline
\end{tabular}




\begin{tabular}{|c|c|}
\hline Study & Reason for exclusion \\
\hline Fries 2005 & All participants secondary RP. \\
\hline Gresele 1992 & Single dose study. No data for subgroups presented. \\
\hline Grigg 1989 & No outcomes for frequency/severity of attacks. \\
\hline Hentzer 1966 & Multiple diagnoses, no data for subgroup of primary RP can be identified. \\
\hline Hiida 1996 & Only one participant (of 19) with primary RP, unable to present statistical data for this subgroup. \\
\hline Holti 1979 & No outcomes for frequency/severity of attacks, no data for subgroup analysis. \\
\hline Janini 1988 & Results presented combined for all participants, no subgroup analysis possible. \\
\hline Jones 1983 & $\begin{array}{l}\text { No distinction between participants with primary and secondary RP, no subgroup analysis possi- } \\
\text { ble. }\end{array}$ \\
\hline Kahan 1985 & $\begin{array}{l}\text { Comparison with calcium channel blocker. Cross-over trial, unclear reporting of results for primary } \\
\text { RP subgroup. }\end{array}$ \\
\hline
\end{tabular}

\begin{tabular}{ll}
\hline Kyle 1992 & Intravenous treatment. \\
\hline Longstaff 1985 & $\begin{array}{l}\text { Results presented combined for all participants, no subgroup analysis possible. No outcomes for } \\
\text { frequency/severity of attacks reported. }\end{array}$
\end{tabular}

\begin{tabular}{ll}
\hline Luderer 1984 & Results presented combined for all participants, no subgroup analysis possible. \\
\hline Malenfant 2011 & St Johns Wort is alternative (complementary) medicine. \\
\hline Marasini 1988 & Results presented combined for all participants, no subgroup analysis possible. \\
\hline Marasini 2004 & All participants secondary RP, intravenous treatment. \\
\hline Maurel 1995 & Participants do not meet inclusion criteria, no outcomes for frequency/severity of attacks. \\
\hline Meloni 1987 & No control group, not a randomised trial, no data for subgroup available. \\
\hline Mohrland 1985 & Intravenous treatment. \\
\hline Murphy 1985 & \begin{tabular}{l} 
Results presented combined for all participants, no subgroup analysis possible. \\
\hline NCT00048763
\end{tabular} \\
$\begin{array}{l}\text { Entry on www.clinicaltrials.gov only. All participants had secondary RP. Results never published. } \\
\text { Pharmaceutical company contacted for further information: "For each study approximately } 51 \text { sub- } \\
\text { jects were planned. For study } 21-01-336 \text { (secondary RP) 23 subjects were enrolled and one subject } \\
\text { completed all periods", "The study was discontinued early due to prolongation of QTc intervals on } \\
\text { ECGs (later attributed to technical problems with ECG machines). The quantity of the data collect- } \\
\text { ed was too small to evaluate efficacy and pharmacokinetics properly". }\end{array}$
\end{tabular}

Entry on www.clinicaltrials.gov only. All participants had primary RP. Results never published. Pharmaceutical company contacted for further information: "For each study approximately 51 subjects were planned. For study 21-02-335 (primary RP) 27 subjects were enrolled and one subject completed all periods", "The study was discontinued early due to prolongation of QTc intervals on ECGs (later attributed to technical problems with ECG machines). The quantity of the data collected was too small to evaluate efficacy and pharmacokinetics properly". 


\begin{tabular}{|c|c|}
\hline Study & Reason for exclusion \\
\hline Nielsen 1983 & $\begin{array}{l}\text { Study includes multiple, increasing doses for some participants, unclear length of treatment for } \\
\text { each participant and dose. }\end{array}$ \\
\hline Nilsen 1979 & $\begin{array}{l}\text { Results presented combined for all participants, no subgroup analysis possible. No outcomes for } \\
\text { frequency/severity of attacks. The evaluated outcomes are not among those evaluated in this re- } \\
\text { view. }\end{array}$ \\
\hline Pancera 1997 & Not a randomised controlled trial. Single blind. \\
\hline Paterna 1997 & No control group, not a randomised trial. \\
\hline Pola 1993 & Intravenous treatment. \\
\hline Rajagopalan 2003 & $\begin{array}{l}\text { Parallel design study, } 19 / 40 \text { primary RP, does not report numbers of participants in treatment and } \\
\text { control group. }\end{array}$ \\
\hline Russell 1985 & Results presented combined for all participants, no subgroup analysis possible. \\
\hline Rustin 1984 & Results presented combined for all participants, no subgroup analysis possible. \\
\hline Sandhagen 1984 & No outcomes for frequency/severity of attacks. \\
\hline Seibold 1984 & No control group, open pilot study. \\
\hline Seibold 1986 & Intravenous treatment. \\
\hline Shawket 1991 & Intravenous treatment. \\
\hline Shcherbakov 1992 & $\begin{array}{l}\text { Parallel design study, } 5 / 16 \text { primary RP, only one participant primary RP in treatment group. Unclear } \\
\text { reporting of outcome. }\end{array}$ \\
\hline Shenoy 2010 & All participants secondary RP. \\
\hline Sunderland 1988 & $\begin{array}{l}\text { Unclear blinding. Outcomes reported as percentages, no numbers given, generally unclear report- } \\
\text { ing of results. }\end{array}$ \\
\hline Tindall 1985 & Results presented combined for all participants, no subgroup analysis possible. \\
\hline Tooke 1990 & Results presented combined for all participants, no subgroup analysis possible. \\
\hline Torley 1990 & All participants secondary RP. \\
\hline Tosi 1987 & No control group, not a randomised trial. \\
\hline Tucker 1999 & Topical application. \\
\hline Wasir 1983 & Study includes calcium channel blocker and non-vasodilator medication. \\
\hline Wesseling 1981 & Single dose study, no results for subgroups. \\
\hline Wise 1994 & Single dose study. \\
\hline Wollersheim 1986 & Results presented combined for all participants, no subgroup analysis possible. \\
\hline Wollersheim 1988 & Open dose-response study, not a randomised trial. \\
\hline
\end{tabular}


RP: Raynaud's phenomenon

Characteristics of ongoing studies [ordered by study ID]

NCT01090492

Trial name or title

A phase 2 a randomised double-blinded, placebo and active controlled two cohort two doses crossover multi-centre clinical study to assess efficacy of a once daily administration of a phosphodiesterase 5 inhibitor (PF-00489791) for the treatment of vasospasm in primary and secondary raynaud's phenomenon.

\begin{tabular}{|c|c|}
\hline Methods & Randomized double blind cross-over trial \\
\hline \multirow[t]{15}{*}{ Participants } & Ages eligible for study: 18 years to 65 years \\
\hline & Genders eligible for study: Both \\
\hline & Accepts healthy volunteers: No \\
\hline & Inclusion Criteria: \\
\hline & -Active Raynaud's Phenomenon \\
\hline & -Stable disease and medication requirements over the previous two months \\
\hline & $\begin{array}{l}\text {-For Secondary Raynaud's Phenomenon subjects, a diagnosis of scleroderma using the American } \\
\text { College of Rheumatology criteria or by the presence of at least } 3 / 5 \text { features of CREST syndrome }\end{array}$ \\
\hline & •both sexes \\
\hline & Exclusion Criteria: \\
\hline & - Uncontrolled hypertension, diabetes mellitus, angina, or using oral nitrates \\
\hline & -Smoking within three months or smoking cessation using nicotine products \\
\hline & -Subjects currently taking sildenafil, tadalafil or vardenafil \\
\hline & -Subjects with ulnar arterial occlusive disease as shown by a modified Allen test \\
\hline & -Pregnant or breast feeding or considering pregnancy in next four months \\
\hline & -Participation in trial for investigational drug within 30 days \\
\hline
\end{tabular}

Interventions

Experimental: Secondary Raynaud 4 mg dose (period 1) Drug: PF-00489791

Subjects with Secondary Raynaud's Phenomenon will receive PF-00489791 4 mg once a day for the first four week cross-over period and then placebo once a day for the second four week cross-over period

Experimental: Secondary Raynaud 4 mg dose (period 2) Drug: PF-00489791

Subjects with Secondary Raynaud's Phenomenon will receive placebo once a day for the first four week cross-over period and then PF-00489791 4 mg once a day for the second four week cross-over period

Experimental: Secondary Raynaud 20 mg dose (period 1) Drug: PF-00489791

Subjects with Secondary Raynaud's Phenomenon will receive PF-00489791 20 mg once a day for the first four week cross-over period and then placebo once a day for the second four week crossover period

Experimental: Secondary Raynaud 20 mg dose (period 2) Drug: PF-00489791 
NCT01090492 (Continued)

Subjects with Secondary Raynaud's Phenomenon will receive placebo once a day for the first four week cross-over period and then PF-00489791 20 mg once a day for the second four week crossover period

Experimental: Primary Raynaud 4 mg dose (period 1) Drug: PF-00489791

Subjects with Primary Raynaud's Phenomenon will receive PF-00489791 4 mg once a day for the first four week cross-over period and then placebo once a day for the second four week cross-over period

Experimental: Primary Raynaud 4 mg dose (period 2) Drug: PF-00489791

Subjects with Primary Raynaud's Phenomenon will receive placebo once a day for the first four week cross-over period and then PF-00489791 $4 \mathrm{mg}$ once a day for the second four week cross-over period

Experimental: Primary Raynaud 20 mg dose (period 1) Drug: PF-00489791

Subjects with Primary Raynaud's Phenomenon will receive PF-00489791 20 mg once a day for the first four week cross-over period and then placebo once a day for the second four week cross-over period

Experimental: Primary Raynaud 20 mg dose (period 2) Drug: PF-00489791

Subjects with Primary Raynaud's Phenomenon will receive placebo once a day for the first four week cross-over period and then PF-00489791 $20 \mathrm{mg}$ once a day for the second four week crossover period

Outcomes

Primary outcome measures:

-Change in the Raynaud's Condition Score during the fourth week of treatment from baseline, comparing active drug to placebo (Time frame: 28 days)

Secondary outcome measures:

-Change in the number of Raynaud's Phenomenon attacks per week during the fourth week of treatment compared to the number of Raynaud's Phenomenon attacks week at baseline (Time frame: 28 days)

-Change in the total duration of Raynaud's Phenomenon attacks per week during the fourth week of treatment compared to the total duration of Raynaud's Phenomenon attacks per week at baseline (Time frame: 28 days)

-Improvements in Raynaud's pain score comparing active to placebo (Time frame: 28 days)

-Decrease ulcer burden in secondary Raynaud's Phenomenon patients by hastening healing or preventing new ulcer emergence (Time frame: 28 days)

-Plasma concentration of PF-00489791 and metabolites (Time frame: 28 days)

-Safety and tolerability of PF-00489791 as assessed by incidences of treatment emergent adverse events and changes from baseline for clinical laboratory tests, vital signs, orthostatic blood pressure measurements and 12-lead ECG parameters (Time frame: 98 days)

Starting date

Study start date: August 2010

Study completion date: May 2011

Primary completion date: May 2011 (Final data collection date for primary outcome measure)
Pfizer CT.gov 
DATA AND ANALYSES

Comparison 1. ACE inhibitor versus placebo

\begin{tabular}{lllll}
\hline Outcome or subgroup title & $\begin{array}{l}\text { No. of } \\
\text { studies }\end{array}$ & $\begin{array}{l}\text { No. of par- } \\
\text { ticipants }\end{array}$ & Statistical method & Effect size \\
\hline 1 Frequency of attacks per week. & 3 & 88 & difference in means (Random, 95\% Cl) & $0.79[0.43,1.16]$ \\
\hline
\end{tabular}

Analysis 1.1. Comparison 1 ACE inhibitor versus placebo, Outcome 1 Frequency of attacks per week..

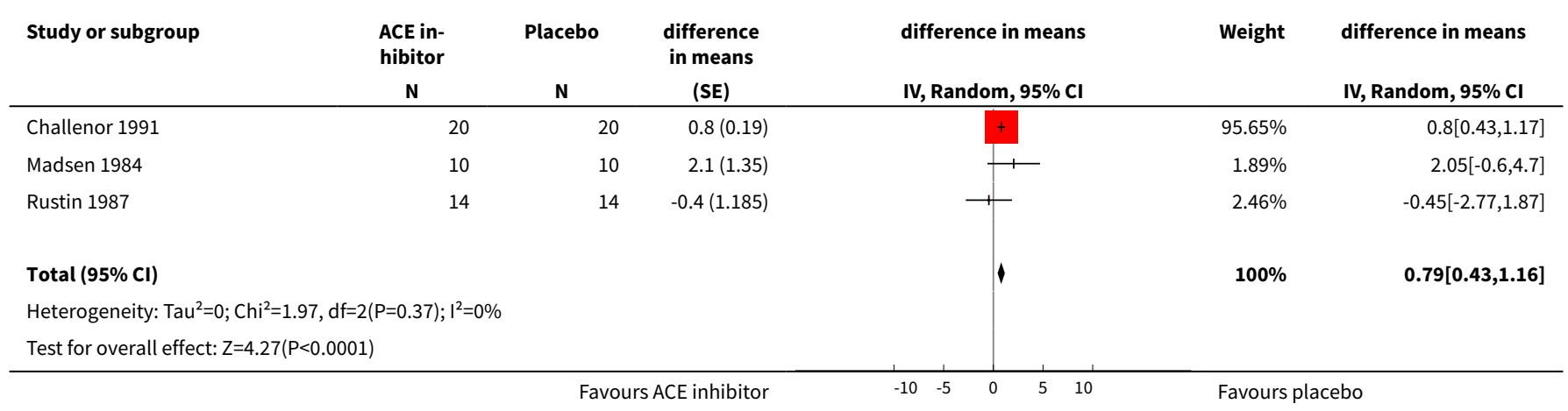

\section{Comparison 2. Captopril versus placebo}

\begin{tabular}{llllll}
\hline Outcome or subgroup title & $\begin{array}{l}\text { No. of } \\
\text { studies }\end{array}$ & $\begin{array}{l}\text { No. of } \\
\text { partici- } \\
\text { pants }\end{array}$ & Statistical method & Effect size \\
\hline 1 Frequency of attacks per week & 2 & 48 & difference in means (Fixed, 95\% Cl) & $0.64[-1.11,2.38]$ \\
\hline 2 Duration per attack (minutes) & 1 & & difference in means (Fixed, 95\% Cl) & Totals not selected \\
\hline
\end{tabular}

Analysis 2.1. Comparison 2 Captopril versus placebo, Outcome 1 Frequency of attacks per week.

\begin{tabular}{|c|c|c|c|c|c|c|}
\hline Study or subgroup & $\begin{array}{c}\text { Captopril } \\
\text { N }\end{array}$ & Placebo & $\begin{array}{l}\text { difference } \\
\text { in means } \\
\text { (SE) }\end{array}$ & $\begin{array}{l}\text { difference in means } \\
\text { IV, Fixed, } 95 \% \mathrm{CI}\end{array}$ & Weight & $\begin{array}{l}\text { difference in means } \\
\text { IV, Fixed, } 95 \% \mathrm{CI}\end{array}$ \\
\hline Madsen 1984 & 10 & 10 & $2.1(1.35)$ & -1- & $43.52 \%$ & $2.05[-0.6,4.7]$ \\
\hline Rustin 1987 & 14 & 14 & $-0.4(1.185)$ & & $56.48 \%$ & $-0.45[-2.77,1.87]$ \\
\hline Total $(95 \% \mathrm{Cl})$ & & & & & $100 \%$ & $0.64[-1.11,2.38]$ \\
\hline \multicolumn{7}{|c|}{ Test for overall effect: $Z=0.72(P=0.47)$} \\
\hline & & & rs captopril & $-10 \quad-5$ & Favour & \\
\hline
\end{tabular}


Analysis 2.2. Comparison 2 Captopril versus placebo, Outcome 2 Duration per attack (minutes).

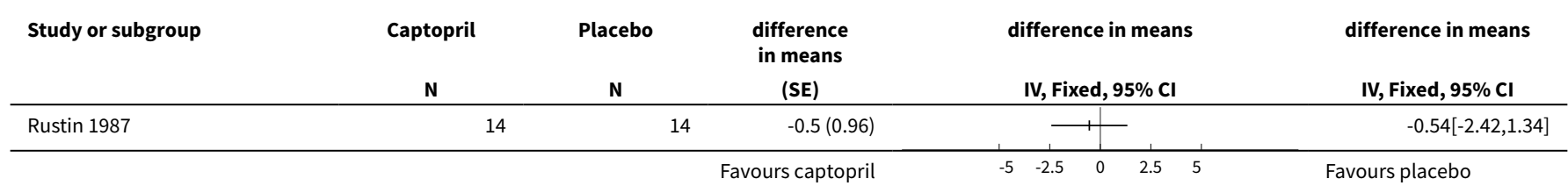

\section{Comparison 3. Enalapril versus placebo}

\begin{tabular}{lllll}
\hline Outcome or subgroup title & $\begin{array}{l}\text { No. of } \\
\text { studies }\end{array}$ & $\begin{array}{l}\text { No. of } \\
\text { partici- } \\
\text { pants }\end{array}$ & Statistical method & Effect size \\
\hline $\begin{array}{l}1 \text { Subjective assessment of improvement }(10 \mathrm{~cm} \mathrm{Vi-} \\
\text { sual Analogue Scale) }\end{array}$ & 1 & & $\begin{array}{l}\text { Mean Difference (IV, Fixed, 95\% } \\
\mathrm{CI})\end{array}$ & $\begin{array}{l}\text { Totals not se- } \\
\text { lected }\end{array}$ \\
\hline
\end{tabular}

Analysis 3.1. Comparison 3 Enalapril versus placebo, Outcome 1 Subjective assessment of improvement (10 cm Visual Analogue Scale).

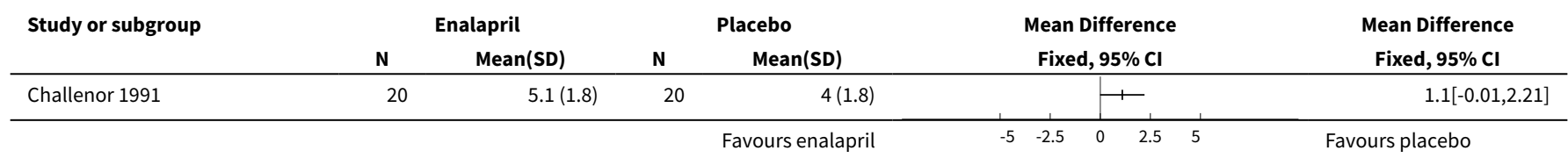

\section{Comparison 4. Buflomedil versus placebo}

\begin{tabular}{lllll}
\hline Outcome or subgroup title & $\begin{array}{l}\text { No. of } \\
\text { studies }\end{array}$ & $\begin{array}{l}\text { No. of } \\
\text { partici- } \\
\text { pants }\end{array}$ & Statistical method & Effect size \\
\hline 1 Frequency of attacks per week & 1 & Mean Difference (IV, Fixed, 95\% CI) & Totals not selected \\
\hline $\begin{array}{l}2 \text { Severity (1:mild, 2:moderate, 3:se- } \\
\text { vere) }\end{array}$ & 1 & Mean Difference (IV, Fixed, 95\% CI) & Totals not selected \\
\hline
\end{tabular}

Analysis 4.1. Comparison 4 Buflomedil versus placebo, Outcome 1 Frequency of attacks per week.

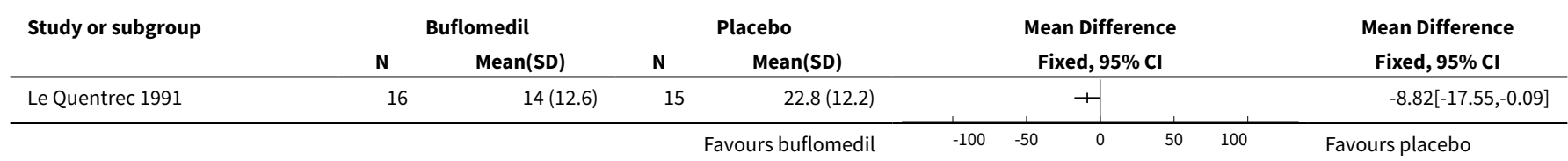


Analysis 4.2. Comparison 4 Buflomedil versus placebo, Outcome 2 Severity (1:mild, 2:moderate, 3:severe).

\begin{tabular}{|c|c|c|c|c|c|c|}
\hline \multirow[t]{2}{*}{ Study or subgroup } & \multicolumn{2}{|c|}{ Buflomedil } & \multicolumn{2}{|c|}{ Placebo } & \multirow{2}{*}{$\begin{array}{c}\text { Mean Difference } \\
\text { Fixed, } 95 \% \mathrm{Cl}\end{array}$} & \multirow{2}{*}{$\begin{array}{c}\text { Mean Difference } \\
\text { Fixed, } 95 \% \mathrm{Cl}\end{array}$} \\
\hline & $\mathbf{N}$ & Mean(SD) & $\mathbf{N}$ & Mean(SD) & & \\
\hline Le Quentrec 1991 & 16 & $1.1(0.6)$ & 15 & $1.5(0.6)$ & 1 & $-0.41[-0.84,0.02]$ \\
\hline
\end{tabular}

\section{Comparison 5. Beraprost versus placebo}

\begin{tabular}{lllll}
\hline Outcome or subgroup title & $\begin{array}{l}\text { No. of } \\
\text { studies }\end{array}$ & $\begin{array}{l}\text { No. of } \\
\text { partici- } \\
\text { pants }\end{array}$ & Statistical method & Effect size \\
\hline 1 Frequency of attacks per week & 1 & Mean Difference (IV, Fixed, 95\% & Totals not selected \\
\hline 2 Severity of attacks (1-4 scale) & 1 & $\begin{array}{l}\text { Mean Difference (IV, Fixed, 95\% } \\
\text { Cl) }\end{array}$ & Totals not selected \\
\hline 3 Disability (100 mm Visual Analogue Scale) & 1 & $\begin{array}{l}\text { Mean Difference (IV, Fixed, 95\% } \\
\text { Cl) }\end{array}$ & Totals not selected \\
\hline 4 Adverse events & 1 & Risk Ratio (M-H, Fixed, 95\% Cl) & Totals not selected \\
\hline
\end{tabular}

Analysis 5.1. Comparison 5 Beraprost versus placebo, Outcome 1 Frequency of attacks per week.

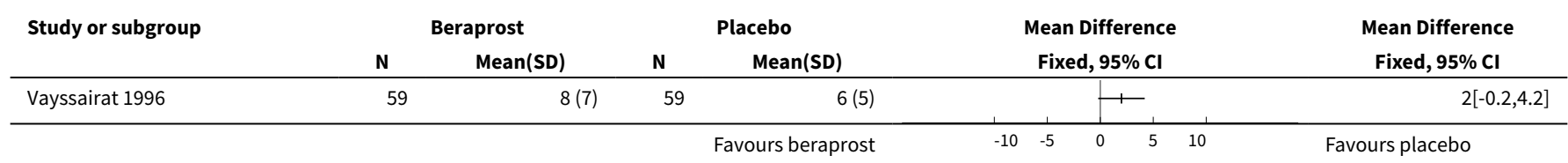

Analysis 5.2. Comparison 5 Beraprost versus placebo, Outcome 2 Severity of attacks (1-4 scale).

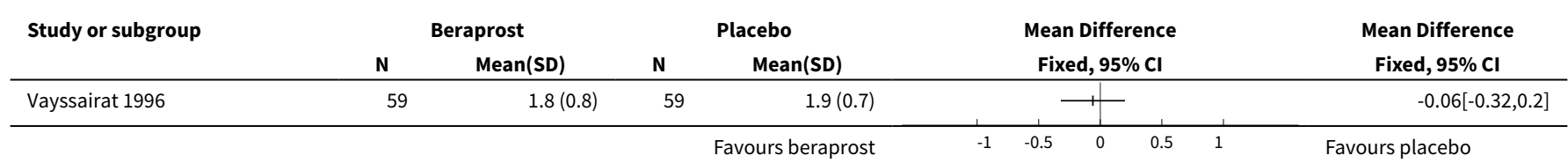

Analysis 5.3. Comparison 5 Beraprost versus placebo, Outcome 3 Disability ( $100 \mathrm{~mm}$ Visual Analogue Scale).

\begin{tabular}{|c|c|c|c|c|c|c|}
\hline \multirow[t]{2}{*}{ Study or subgroup } & \multicolumn{2}{|c|}{ Beraprost } & \multicolumn{2}{|c|}{ Placebo } & \multirow{2}{*}{$\begin{array}{c}\text { Mean Difference } \\
\text { Fixed, } 95 \% \mathrm{Cl}\end{array}$} & \multirow{2}{*}{$\begin{array}{c}\text { Mean Difference } \\
\text { Fixed, } 95 \% \mathrm{Cl}\end{array}$} \\
\hline & $\mathbf{N}$ & $\operatorname{Mean}(S D)$ & $\mathbf{N}$ & Mean(SD) & & \\
\hline Vayssairat 1996 & 59 & $39(28)$ & 59 & $36(26)$ & + & $3[-6.75,12.75]$ \\
\hline
\end{tabular}


Analysis 5.4. Comparison 5 Beraprost versus placebo, Outcome 4 Adverse events.

\begin{tabular}{|c|c|c|c|c|c|c|}
\hline \multirow{2}{*}{$\begin{array}{l}\text { Study or subgroup } \\
\text { Vayssairat } 1996\end{array}$} & $\begin{array}{c}\text { Beraprost } \\
\mathrm{n} / \mathrm{N}\end{array}$ & $\begin{array}{c}\text { Placebo } \\
n / N\end{array}$ & \multicolumn{3}{|c|}{$\begin{array}{c}\text { Risk Ratio } \\
\text { M-H, Fixed, 95\% Cl }\end{array}$} & \multirow{2}{*}{ 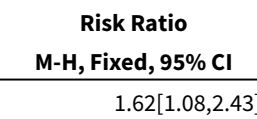 } \\
\hline & $34 / 59$ & $21 / 59$ & & & 1 & \\
\hline
\end{tabular}

\section{Comparison 6. Dazoxiben versus placebo}

\begin{tabular}{lllll}
\hline Outcome or subgroup title & $\begin{array}{l}\text { No. of } \\
\text { studies }\end{array}$ & $\begin{array}{l}\text { No. of par- } \\
\text { ticipants }\end{array}$ & Statistical method & Effect size \\
\hline 1 Frequency of attacks per week & 1 & difference in means (Fixed, 95\% Cl) & Totals not selected \\
\hline
\end{tabular}

Analysis 6.1. Comparison 6 Dazoxiben versus placebo, Outcome 1 Frequency of attacks per week.

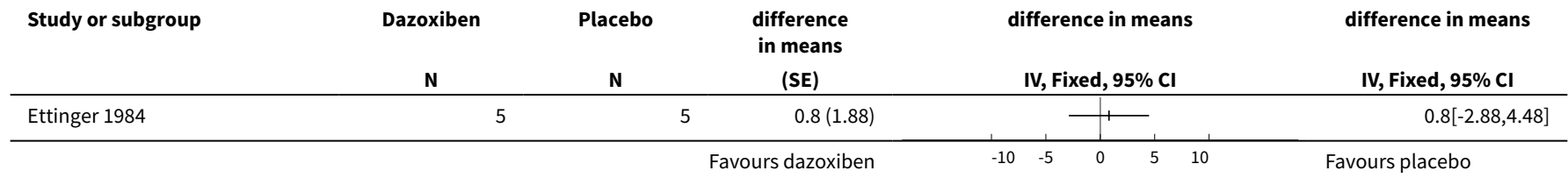

\section{Comparison 7. Ketanserin versus placebo}

\begin{tabular}{lllll}
\hline Outcome or subgroup title & $\begin{array}{l}\text { No. of } \\
\text { studies }\end{array}$ & $\begin{array}{l}\text { No. of } \\
\text { partici- } \\
\text { pants }\end{array}$ & Statistical method & Effect size \\
\hline 1 Frequency of attacks per week & 1 & Mean Difference (IV, Fixed, 95\% Cl) & Totals not selected \\
\hline $\begin{array}{l}\text { 2 Duration of attacks per day } \\
\text { (minutes) }\end{array}$ & 1 & Mean Difference (IV, Fixed, 95\% Cl) & Totals not selected \\
\hline $\begin{array}{l}3 \text { Severity score (frequency of at- } \\
\text { tacks/day X duration of attacks) }\end{array}$ & 1 & Mean Difference (IV, Fixed, $95 \% \mathrm{Cl})$ & Totals not selected \\
\hline 4 Adverse events & 1 & Risk Ratio (M-H, Fixed, 95\% Cl) & Totals not selected \\
\hline
\end{tabular}

Analysis 7.1. Comparison 7 Ketanserin versus placebo, Outcome 1 Frequency of attacks per week.

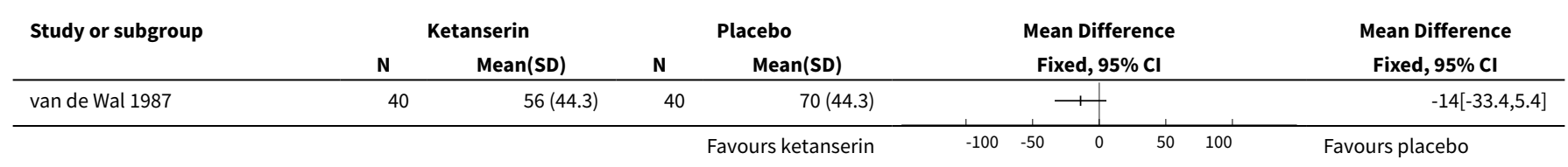


Analysis 7.2. Comparison 7 Ketanserin versus placebo, Outcome 2 Duration of attacks per day (minutes).

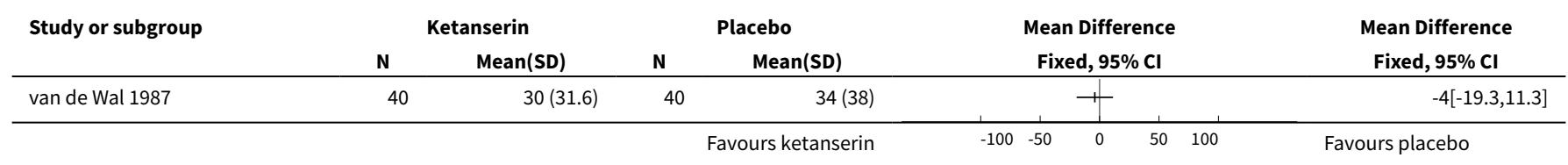

Analysis 7.3. Comparison 7 Ketanserin versus placebo, Outcome 3 Severity score (frequency of attacks/day X duration of attacks).

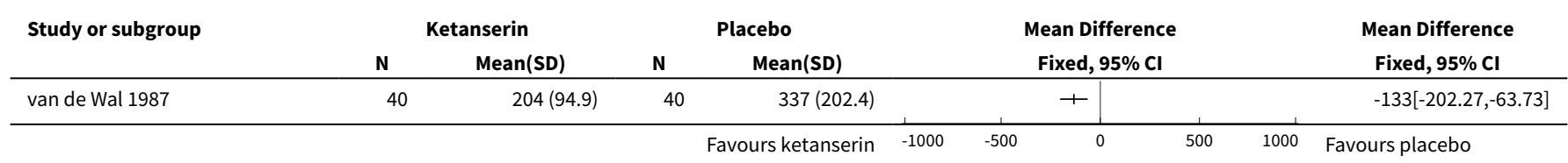

Analysis 7.4. Comparison 7 Ketanserin versus placebo, Outcome 4 Adverse events.

\begin{tabular}{|c|c|c|c|c|c|c|}
\hline \multirow{2}{*}{$\begin{array}{l}\text { Study or subgroup } \\
\text { van de Wal } 1987\end{array}$} & $\begin{array}{c}\text { Ketanserin } \\
\mathrm{n} / \mathrm{N} \\
\end{array}$ & $\begin{array}{c}\text { Placebo } \\
n / N\end{array}$ & \multicolumn{3}{|c|}{$\begin{array}{c}\text { Risk Ratio } \\
\text { M-H, Fixed, 95\% Cl }\end{array}$} & \multirow{2}{*}{$\begin{array}{c}\begin{array}{c}\text { Risk Ratio } \\
\text { M-H, Fixed, 95\% Cl }\end{array} \\
1.54[0.89,2.65\end{array}$} \\
\hline & $20 / 40$ & $13 / 40$ & & & 1 & \\
\hline
\end{tabular}

Comparison 8. Moxisylyte (Thymoxamine) versus placebo

\begin{tabular}{lllll}
\hline Outcome or subgroup title & $\begin{array}{l}\text { No. of } \\
\text { studies }\end{array}$ & $\begin{array}{l}\text { No. of par- } \\
\text { ticipants }\end{array}$ & Statistical method & Effect size \\
\hline 1 Adverse events & 1 & Risk Ratio (M-H, Fixed, $95 \% \mathrm{Cl})$ & Totals not selected \\
\hline
\end{tabular}

Analysis 8.1. Comparison 8 Moxisylyte (Thymoxamine) versus placebo, Outcome 1 Adverse events.

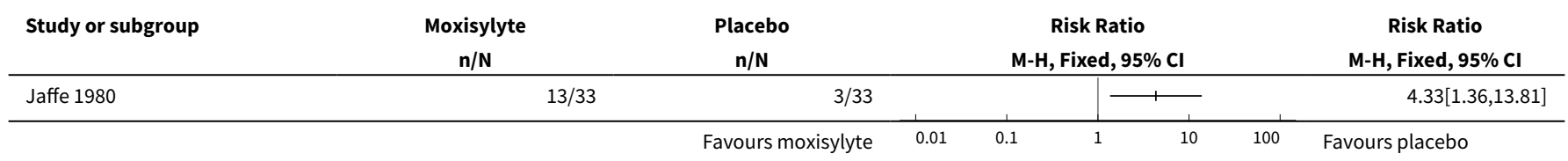




\section{Comparison 9. Any drug versus placebo}

\begin{tabular}{lllll}
\hline Outcome or subgroup title & $\begin{array}{l}\text { No. of } \\
\text { studies }\end{array}$ & $\begin{array}{l}\text { No. of } \\
\text { partici- } \\
\text { pants }\end{array}$ & Statistical method & Effect size \\
\hline $\begin{array}{l}1 \text { Differences in mean frequencies of attacks per } \\
\text { week }\end{array}$ & & & $\begin{array}{l}\text { difference in means (Fixed, 95\% } \\
\mathrm{Cl})\end{array}$ & $\begin{array}{l}\text { Totals not select- } \\
\text { ed }\end{array}$
\end{tabular}

Analysis 9.1. Comparison 9 Any drug versus placebo, Outcome 1 Differences in mean frequencies of attacks per week.

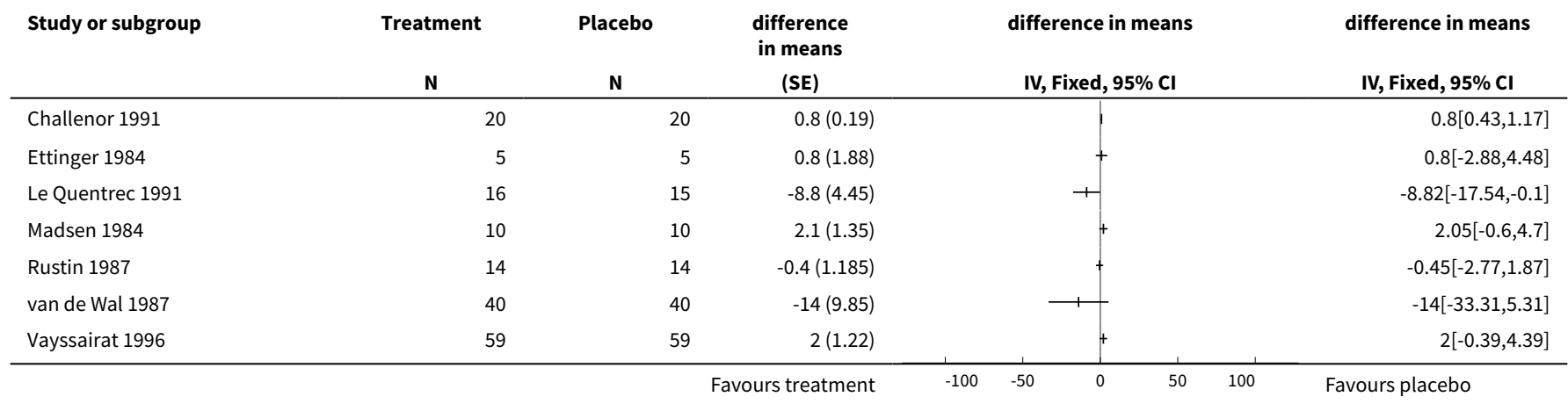

\section{ADDITIONAL TABLES}

Table 1. Classification of drugs with vasodilator effects, from BNF 53 (non-oral excluded)

\begin{tabular}{llll}
\hline BNF chapter & Class & ATC code & Generic name \\
\hline 2.5 .1 & $\begin{array}{l}\text { Vasodilator antihypertensive drugs } \\
\text { including prostacyclin analogues }\end{array}$ & C02D, B01A & Bosentan, hydralazine, iloprost, sildenafil \\
\hline 2.5 .4 & Alpha adrenoreceptor blocking drugs & C02C & Doxazosin, indoramin, prazosin, terazosin, urapidil \\
\hline Serotonin antagonists & C02KD & Ketanserin \\
\hline 2.5 .5 .1 & $\begin{array}{l}\text { Angiotensin-converting enzyme in- } \\
\text { hibitors }\end{array}$ & C09A & $\begin{array}{l}\text { Captopril, cilazapril, enalapril maleate, fosinopril sodium, } \\
\text { imidapril hydrochloride, lisinopril, moexipril hydrochloride, } \\
\text { perindopril erbumine, quinalapril, ramipril, trandolapril }\end{array}$ \\
\hline 2.5 .5 .2 & Angiotensin-II receptor antagonists & C09C & $\begin{array}{l}\text { Candesartan cilexitil, eprosartan, losartan potassium, } \\
\text { olmesartan medoxomil, telmisartan, valsartan }\end{array}$ \\
\hline 2.6 .4 & Nitrates & C01D & $\begin{array}{l}\text { Glyceryl trinitrate, isosorbide dinitrate, isosorbide mononi- } \\
\text { trate }\end{array}$ \\
\hline 4.3 .3 & $\begin{array}{l}\text { Selective Serotonin Reuptake In- } \\
\text { hibitors }\end{array}$ & N06A B & $\begin{array}{l}\text { Citalopram, escitalopram, fluoxetine, fluvoxamine maleate, } \\
\text { paroxetine, sertraline }\end{array}$ \\
\hline
\end{tabular}


Table 1. Classification of drugs with vasodilator effects, from BNF 53 (non-oral excluded) (Continued)

\begin{tabular}{llll}
4.6 & Antihistamines & N07CA & Cinnarizine \\
\hline 7.4 .5 & Phosphodiesterase type-5 inhibitors & G04B E & Sildenafil, tadalafil, vardenafil \\
\hline
\end{tabular}

Table 2. Included and excluded trials presented by BNF chapter and ATC code

BNF Chap- Class ATC Code Trials
ter

2.5.1 Vasodilator antihyper- C02D, Included: Vayssairat 1996

7.4.5 tensive drugs and prosta- B01A, Excluded: Bali 2011, Belch 1995, Cabane 1985, Caglayan 2006, Caglayan cyclin analogues/ phos- G04BE 2011, Dompeling 1992, Drury 1985, Friedman 2007, Fries 2005, Hiida phodiesterase type-5 in- $\quad$ 1996, Kyle 1992, Marasini 2004, Mohrland 1985, Pola 1993, Shawket hibitors 1991, Shenoy 2010, Torley 1990, Wise 1994

\begin{tabular}{|c|c|c|c|}
\hline 2.5.4 & $\begin{array}{l}\text { Alpha adrenoreceptor } \\
\text { blocking drugs }\end{array}$ & $\mathrm{C} 02 \mathrm{C}$ & $\begin{array}{l}\text { Included: None } \\
\text { Excluded: Clement 1986, Cleophas 1984, Kahan 1985, Nielsen 1983, Pa- } \\
\text { terna 1997, Russell 1985, Wollersheim 1986, Wollersheim } 1988\end{array}$ \\
\hline
\end{tabular}

\begin{tabular}{lll}
\hline $\begin{array}{l}\text { Serotonin antagonists } \\
\text { (Ketanserin) }\end{array}$ & C02KD & Included: van de Wal 1987 \\
& & Excluded: Arneklo-Nobin 1988, Arosio 1989, Arosio 1991, Codella 1989, \\
& Coffman 1989, Dormandy 1988, Longstaff 1985, Marasini 1988, Meloni \\
& 1987, Seibold 1984, Seibold 1986, Tooke 1990 \\
\hline
\end{tabular}

\begin{tabular}{llll}
\hline 2.5.5.1 & $\begin{array}{l}\text { Angiotensin-converting } \\
\text { enzyme inhibitors }\end{array}$ & C09A & $\begin{array}{l}\text { Included: Challenor 1991, Madsen 1984, Rustin 1987 } \\
\text { Excluded: Dowie 1990, Janini 1988, Shcherbakov 1992, Tosi 1987 }\end{array}$ \\
\hline 2.5.5.2 & $\begin{array}{l}\text { Angiotensin-II receptor } \\
\text { antagonists }\end{array}$ & C09C & $\begin{array}{l}\text { Included: None } \\
\text { Excluded: Dziadzio 1999, Pancera 1997 }\end{array}$ \\
\hline
\end{tabular}

\begin{tabular}{|c|c|c|c|}
\hline 2.6.1 & Nitrates & C01D & $\begin{array}{l}\text { Included: None } \\
\text { Excluded: None }\end{array}$ \\
\hline
\end{tabular}

\begin{tabular}{|c|c|c|c|}
\hline 2.6 .4 & $\begin{array}{l}\text { Peripheral vasodilators } \\
\text { and related drugs }\end{array}$ & C04A & $\begin{array}{l}\text { Included: Jaffe 1980, Le Quentrec } 1991 \\
\text { Excluded: Bounameaux 1986, Courbier 1981, Davinroy 1993, Dumoulin } \\
\text { 1981, Grigg 1989, Hentzer 1966, Holti 1979, Maurel 1995, Murphy 1985, } \\
\text { NCT00048763, NCT00048776, Nilsen 1979, Rajagopalan 2003, Sunder- } \\
\text { land 1988, Wesseling } 1981\end{array}$ \\
\hline
\end{tabular}

\begin{tabular}{llll}
\hline 4.3 .3 & $\begin{array}{l}\text { Selective Serotonin Re- } \\
\text { uptake Inhibitors }\end{array}$ & N06A B & $\begin{array}{l}\text { Included: None } \\
\text { Excluded: Coleiro 2001 }\end{array}$ \\
\hline 4.6 & Antihistamines & N07CA & $\begin{array}{l}\text { Included: None } \\
\text { Excluded: None }\end{array}$ \\
\hline
\end{tabular}

Other (incl. Bradilan,Da- Included: Ettinger 1984

zoxiben, UK-38,485, Excluded: Arnot 1978, Belch 1983, Bredie 2012, Bunker 1991, Bunker

(Dazmegrel) 1993, Choi 2009, Csiki 2011, Gresele 1982, Jones 1983, Luderer 1984, Malenfant 2011, NCT01233999, Rustin 1984, Sandhagen 1984, Tindall 1985, Tucker 1999, Wasir 1983 
Table 3. Identified drugs presented by BNF chapter and ATC codes

\begin{tabular}{|c|c|c|c|}
\hline BNF & Class & ATC code & Drug name \\
\hline $\begin{array}{l}2.5 .1 \\
7.4 .5\end{array}$ & $\begin{array}{l}\text { Vasodilator antihypertensive } \\
\text { drugs including prostacyclin } \\
\text { analogues. Phosphodiesterase } \\
\text { type-5 inhibitors }\end{array}$ & $\begin{array}{l}\text { C02D, B01A, } \\
\text { G04BE }\end{array}$ & $\begin{array}{l}\text { Included: Beraprost } \\
\text { Excluded: Alprostadil, sildenafil, tadalafil, vardenafil, car- } \\
\text { baprostacyclin, iloprost, misoprostol, Calcitonin Gene Related } \\
\text { Peptide (CGRP), prostaglandin E1 }\end{array}$ \\
\hline \multirow[t]{2}{*}{2.5 .4} & $\begin{array}{l}\text { Alpha adrenoreceptor blocking } \\
\text { drugs }\end{array}$ & $\mathrm{CO} C \mathrm{C}$ & $\begin{array}{l}\text { Included: None } \\
\text { Excluded: Indoramin, phenoxybenzamine, prazosin, terazosin }\end{array}$ \\
\hline & Serotonin antagonists & $\mathrm{C} 02 \mathrm{KD}$ & $\begin{array}{l}\text { Included : Ketanserin } \\
\text { Excluded: No other drug found }\end{array}$ \\
\hline 2.5.5.1 & $\begin{array}{l}\text { Angiotensin-converting enzyme } \\
\text { inhibitors }\end{array}$ & Co9A & $\begin{array}{l}\text { Included: Captopril, enalapril } \\
\text { Excluded: No other drug found }\end{array}$ \\
\hline 2.5.5.2 & $\begin{array}{l}\text { Angiotensin-II receptor antago- } \\
\text { nists }\end{array}$ & Co9C & $\begin{array}{l}\text { Included: None } \\
\text { Excluded: Losartan }\end{array}$ \\
\hline 2.6.1 & Nitrates & C01D & None \\
\hline 2.6.4 & $\begin{array}{l}\text { Peripheral vasodilators and relat- } \\
\text { ed drugs }\end{array}$ & C04A & $\begin{array}{l}\text { Included: Buflomedil, moxisylyte } \\
\text { Excluded: Cilostazol, inositol nicotinate, isoxsuprine, naftidro- } \\
\text { furyl oxalate, suloctidil, pentoxifylline }\end{array}$ \\
\hline 4.3 .3 & $\begin{array}{l}\text { Selective Serotonin Reuptake In- } \\
\text { hibitors }\end{array}$ & N06AB & $\begin{array}{l}\text { Included: None } \\
\text { Excluded: Fluoxetine }\end{array}$ \\
\hline \multirow[t]{2}{*}{4.6} & Antihistamines & N07CA & None \\
\hline & Others & & $\begin{array}{l}\text { Included: Dazoxiben } \\
\text { Excluded: Botulinum, bradilan, dipyridamole, felodipin, ginkgo } \\
\text { biloba extract EGb 761, histamine and neuropeptides, nifedip- } \\
\text { ine, metoprolol, nitric oxide, pinacidil, reserpine, st Johns wort, } \\
\text { trifluoperazine, UK-38,485 (dazmegrel) }\end{array}$ \\
\hline
\end{tabular}

Table 4. Concealment of allocation and Jadad scores

\begin{tabular}{|c|c|c|}
\hline Study ID & $\begin{array}{l}\text { Concealment } \\
\text { score }\end{array}$ & Jadad score \\
\hline Challenor 1991 & B & $3 / 5$ \\
\hline Ettinger 1984 & B & $3 / 5$ \\
\hline Jaffe 1980 & B & $3 / 5$ \\
\hline Le Quentrec 1991 & $A$ & $5 / 5$ \\
\hline Madsen 1984 & B & $3 / 5$ \\
\hline Rustin 1987 & B & $3 / 5$ \\
\hline van de Wal 1987 & B & $3 / 5$ \\
\hline
\end{tabular}


Table 4. Concealment of allocation and Jadad scores (Continued)

\section{AP PEN DICES}

\section{Appendix 1. CENTRAL search strategy}

\begin{tabular}{|c|c|c|}
\hline$\# 1$ & MeSH descriptor Raynaud Disease explode all trees & 263 \\
\hline \#2 & Raynaud* & 575 \\
\hline \#3 & (\#1 OR \#2) & 576 \\
\hline \#4 & MeSH descriptor Vasodilator Agents explode all trees & 3202 \\
\hline \#5 & MeSH descriptor Vasodilation, this term only & 1516 \\
\hline \#6 & $\begin{array}{l}\text { bosentan or iloprost or sildenafil or doxazosin or indoramin or prazosin or terazosin or } \\
\text { ketanserin or captopril or cilazipril or losartan or candesartan or cilostazol or naftidro- } \\
\text { furyl or pentoxifylline or cinnarizine }\end{array}$ & 8046 \\
\hline$\# 7$ & $\begin{array}{l}\text { capoten or enalapril or innovace or fosinopril or staril or lisinopril or carace or zestril or vi- } \\
\text { vatec or cilazapril or vascace or ramipril or triatec or trandolapril or gopten or imidapril or } \\
\text { tanatril or moexipril or perdix or perindopril or coversyl or quinapril or accupro }\end{array}$ & 5238 \\
\hline \#8 & MeSH descriptor Angiotensin-Converting Enzyme Inhibitors explode all trees & 3495 \\
\hline \#9 & $\begin{array}{l}\text { losartan or cozaar or eprosartan or teveten or diovan or valsartan or aprovel or irbesartan } \\
\text { or atacand or candesartan or amias or micardis or telmisartan or olmetec or olmesartan }\end{array}$ & 3125 \\
\hline \#10 & alpha near4 block* & 1256 \\
\hline \#11 & angiotensin near4 enzyme* & 5900 \\
\hline \#12 & ACE near3 inhib* & 3047 \\
\hline \#13 & angiotensin near4 antagonist* & 1719 \\
\hline \#14 & serotonin near4 inhibitor & 3480 \\
\hline \#15 & serotonin near4 antagon* & 1370 \\
\hline \#16 & MeSH descriptor Serotonin Antagonists explode all trees & 925 \\
\hline \#17 & MeSH descriptor Serotonin Uptake Inhibitors explode all trees & 2101 \\
\hline$\# 18$ & $\begin{array}{l}\text { fluoxetine or fluoksetin or prozac or fontex or citalopram or cipramil or escitalopram or } \\
\text { cipralex or fluvoxamine or faverin or fevarin or paroxetine or paroxetin or seroxat or ser- } \\
\text { traline or zoloft or lustral }\end{array}$ & 6603 \\
\hline \#19 & beraprost or bosentan or tracleer or alprostadil or iloprost or ventavis & 1148 \\
\hline
\end{tabular}


(Continued)

\begin{tabular}{|c|c|c|}
\hline \#20 & sildenafil or revatio or viagra or tadalafil or cialis or vardenafil or levitra & 987 \\
\hline \#21 & phosphodiesterase near4 inhibitor & 1129 \\
\hline \#22 & glyceryl trinitrate & 1005 \\
\hline \#23 & MeSH descriptor Isosorbide Dinitrate, this term only & 845 \\
\hline \#24 & naftidrofuryl or praxilene & 234 \\
\hline \#25 & hydralazine or apresoline & 535 \\
\hline \#26 & inositol or hexopal & 304 \\
\hline$\# 27$ & cinnarizine or stugeron & 197 \\
\hline \#28 & cilostazol or pletal & 285 \\
\hline \#29 & pentoxifylline or trental & 852 \\
\hline \#30 & $\begin{array}{l}\text { prazosin or hypovasc or minipress or doxazosin or cardura or carduran or terazosin or in- } \\
\text { doramin or baratol or hytrin or doralese or urapidil }\end{array}$ & 1511 \\
\hline \#31 & moxisylyte or thymoxamine or opilon & 79 \\
\hline \#32 & ketanserin or sufrexal & 460 \\
\hline \#33 & $\begin{array}{l}\text { (\#4 OR \#5 OR \#6 OR \#7 OR \#8 OR \#9 OR \#10 OR \#11 OR \#12 OR \#13 OR \#14 OR \#15 OR \#16 } \\
\text { OR \#17 OR \#18 OR \#19 OR \#20 OR \#21 OR \#22 OR \#23 OR \#24 OR \#25 OR \#26 OR \#27 OR \#28 } \\
\text { OR \#29 OR \#30 OR \#31 OR \#32) }\end{array}$ & 31644 \\
\hline \#34 & (\#3 AND \#33) & 167 \\
\hline
\end{tabular}

\section{Appendix 2. MEDLINE search strategy searched July 2007}

1.RANDOMIZED CONTROLLED TRIAL.pt.

2.CONTROLLED CLINICAL TRIAL.pt.

3.RANDOMIZED CONTROLLED TRIALS/

4.RANDOM ALLOCATION/

5.DOUBLE BLIND METHOD/

6.SINGLE BLIND METHOD/

7.or/1-6

8.(ANIMALS not HUMANS).sh.

9.7 not 8

10.CLINICAL TRIAL.pt.

11.exp CLINICAL TRIALS/

12. (clin\$ adj25 trial\$).ti,ab.

13.((singl\$ or doubl\$ or trebl\$ or tripl\$) adj25 (blind\$ or mask\$)).ti,ab.

14.PLACEBOS/

15. placebo\$.ti,ab.

16.random \$.ti,ab.

17.RESEARCH DESIGN/

18.or/10-17

19.18 not 8

20.19 not 9

21.9 or 20

22.exp VASODILATOR AGENTS/ or (vasodilator adj5 (agent or drug\$)).ti,ab. 
23. (capoten or captopril or enalapril or innovace or fosinopril or staril or lisinopril or carace or zestril or vivatec or cilazapril or vascace or ramipril or triatec or trandolapril or gopten or imidapril or tanatril or moexipril or perdix or perindopril or coversyl or quinapril or accupro).ti,ab.

24.ACE inhibitor.ti,ab. or exp ANGIOTENSIN-CONVERTING ENZYME INHIBITORS/

25. (losartan or cozaar or eprosartan or teveten or diovan or valsartan or aprovel or irbesartan or atacand or candesartan or amias or micardis or telmisartan or olmetec or olmesartan).ti,ab.

26.(angiotensin adj5 receptor adj5 antagonist).ti,ab.

27.ANGIOTENSIN-II/ or angiotensin-II receptor antagonist.ti,ab.

28.exp SEROTONIN ANTAGONISTS/ or exp SEROTONIN UPTAKE INHIBITORS/ or SSRI\$.ti,ab.

29.(fluoxetine or fluoksetin or prozac or fontex or citalopram or cipramil or escitalopram or cipralex or fluvoxamine or faverin or fevarin or paroxetine or paroxetin or seroxat or sertraline or zoloft or lustral).ti,ab.

30.exp EPOPROSTENOL/ or (prostacycl\$ adj5 analogue\$).ti,ab.

31.(beraprost or bosentan or tracleer or alprostadil or iloprost or ventavis).ti,ab.

32.(sildenafil or revatio or viagra or tadalafil or cialis or vardenafil or levitra).ti,ab.

33.((phosphodiesterase adj5 inhibitor) or PDE5).ti,ab.

34.glyceryl trinitrate.ti,ab.

35.ISOSORBIDE DINITRATE/ or isosorbide mononitrate.ti,ab.

36.(naftidrofuryl oxalate or praxilene).ti,ab.

37.(hydralazine or apresoline).ti,ab.

38. (inositol nicotinate or hexopal).ti,ab.

39.exp HISTAMINE ANTAGONISTS/

40. (cinnarizine or stugeron).ti,ab.

41. (cilostazol or pletal).ti,ab.

42.(pentoxifylline or trental).ti,ab.

43. (prazosin or hypovasc or minipress or doxazosin or cardura or carduran or terazosin or indoramin or baratol or hytrin or doralese or urapidil).ti,ab.

44.exp ADRENERGIC ALPHA-ANTAGONISTS/ or (alpha adj5 adren\$ adj5 (drug\$ or agent\$)).ti,ab.

45.(moxisylyte or thymoxamine or opilon).ti,ab.

46.(ketanserin or sufrexal).ti,ab.

47.(or/22-46)

48.RAYNAUD DISEASE/

49.(raynaud\$ adj5 disease).ti,ab.

50.(digital adj5 vasospasm\$).ti,ab.

51.or/48-50

52.(21 and 47 and 51)

\section{Appendix 3. EMBASE search strategy searched July 2007}

1.random\$.ti,ab.

2.factorial\$.ti,ab.

3.(crossover\$ or cross over\$ or cross-over).ti,ab.

4.placebo\$.ti,ab.

5.(doubl\$ adj blind\$).ti,ab.

6.(singl\$ adj blind\$).ti,ab.

7.assign\$.ti,ab.

8.allocat\$.ti,ab.

9.volunteer\$.ti,ab.

10.CROSSOVER PROCEDURE/

11.DOUBLE-BLIND PROCEDURE/

12.RANDOMIZED CONTROLLED TRIAL/

13.SINGLE-BLIND PROCEDURE/

14.or/1-13

15.exp ANIMAL/ or NONHUMAN/ or exp ANIMAL EXPERIMENT/

16.exp HUMAN/

17.16 and 15

18.15 not 17

19.14 not 18

20.exp VASODILATOR AGENT/ or (vasodilator and (agents or drug\$)).ti,ab.

21.(peripheral vasodilator agent).ti,ab.

22. (capoten or captopril or enalapril or innovace or fosinopril or staril or lisinopril or carace or zestril or vivatec or cilazapril or vascace or ramipril or triatec or tritace or trandolapril or gopten or imidapril or tanatril or moexipril or perdix or perindopril or coversyl or quinapril or accupro).ti,ab. 
23.(ACE inhibitor or angiotensin converting enzyme inhibitor).ti,ab.

24.(losartan or cozaar or eprosartan or teveten or diovan or valsartan or aprovel or irbesartan or atacand or candesartan or amias or micardis or telmisartan or olmetec or olmesartan).ti,ab.

25.(angiotensin adj5 receptor adj5 antagonist).ti,ab.

26.exp ANGIOTENSIN 2 RECEPTOR ANTAGONIST/ or exp ANGIOTENSIN/ or exp ANGIOTENSIN RECEPTOR ANTAGONIST/

27.exp SEROTONIN UPTAKE INHIBITOR/ or (serotonin adj5 (receptor or antagonist)).ti,ab.

28. (fluoxetine or fluoksetin or prozac or fontex or citalopram or cipramil or escitalopram or cipralex or fluvoxamine or faverin or fevarin or paroxetine or paroxetin or seroxat or sertraline or zoloft or lustral).ti,ab.

29.(prostacycl\$ adj5 analogue\$).ti,ab.

30.(beraprost or bosentan or tracleer or epoprostenol or flolan or alprostadil or iloprost or ventavis).ti,ab.

31.(sildenafil or viagra or revatio or tadalafil or cialis or vardenafil or levitra).ti,ab.

32.exp PHOSPHODIESTERASE INHIBITOR/ or exp PHOSPHODIESTERASE V INHIBITOR/ or ((phosphodiesterase adj5 inhibitor) or PDE5).ti,ab.

33.ISOSORBIDE DINITRATE/ or GLYCERYL TRINITRATE/ or (isosorbide trinitrate).ti,ab.

34.(naftidrofuryl oxalate or praxilene).ti,ab.

35.(hydralazine or apresoline).ti,ab.

36.(inositol nicotinate or hexopal).ti,ab.

37.exp ANTIHISTAMINIC AGENT/

38.(cinnarizine or stugeron).ti,ab.

39. (cilostazol or pletal).ti,ab.

40.(pentoxifylline or trental).ti,ab.

41. (prazosin or hypovasc or minipress or doxazosin or cardura or carduran or terazosin or indoramin or baratol or hytrin or doralese or urapidil).ti,ab.

42.exp ALPHA ADRENERGIC RECEPTOR BLOCKING AGENT/ or (alpha adren\$ adj5 agent).ti,ab.

43.(moxisylyte or thymoxamine or opilon).ti,ab.

44.(ketanserin or sufrexal).ti,ab.

45.(or/20-44)

46. RAYNAUD PHENOMENON/

47.(raynaud\$ adj5 disease).ti,ab.

48.(digital adj5 vasospasm\$).ti,ab.

49.or/46-48

50.19 and 45 and 49

\section{WHAT'S NEW}

\begin{tabular}{lll}
\hline Date & Event & Description \\
\hline 15 May 2012 & $\begin{array}{l}\text { New citation required but conclusions } \\
\text { have not changed }\end{array}$ & $\begin{array}{l}\text { Review updated. New author (JM) joined and one author (BV) } \\
\text { stepped down from the review team. Eleven additional stud- } \\
\text { ies excluded and one ongoing study added. Conclusions not } \\
\text { changed. }\end{array}$ \\
\hline 15 May 2012 New search has been performed & $\begin{array}{l}\text { Review updated, searches updated. For this update we identi- } \\
\text { fied an additional 15 articles for possible inclusion. Eleven were } \\
\text { excluded and one was a second reference to a previously ex- } \\
\text { cluded study. We found one ongoing study and two articles were } \\
\text { deemed not relevant. }\end{array}$ \\
\hline
\end{tabular}

\section{H I S T ORY}

Protocol first published: Issue 3, 2007

Review first published: Issue 2, 2008

\begin{tabular}{lll}
\hline Date & Event & Description \\
\hline 30 April 2008 & Amended & Converted to new review format. \\
\hline
\end{tabular}

Oral vasodilators for primary Raynaud's phenomenon (Review) 


\begin{tabular}{lll}
\hline Date & Event & Description \\
\hline 18 December 2007 & $\begin{array}{l}\text { New citation required and conclusions } \\
\text { have changed }\end{array}$ & Substantive amendment \\
\hline
\end{tabular}

\section{CONTRIBUTIONS OF AUTHORS}

For the 2008 version of the review:

Bergljot Vinjar identified possible trials, considered them for inclusion, assessed their quality and performed data extraction. She contacted study investigators and pharmaceutical companies. She wrote the draft of the review.

Marlene Stewart considered trials for inclusion, assessed their quality and checked the data extraction and commented on the draft review.

For this update of the review:

Marlene Stewart considered trials for inclusion and updated the text of the review.

Joanne Morling considered trials for inclusion and commented on the text of the review.

\section{DECLARATIONS OF INTEREST}

None known

\section{SOURCES OF SUPPORT}

\section{Internal sources}

- No sources of support supplied

\section{External sources}

- Chief Scientist Office, Scottish Government Health Directorates, Scottish Government, UK.

The PVD Group editorial base is supported by the Chief Scientist Office.

\section{N DEX TERMS}

\section{Medical Subject Headings (MeSH)}

Administration, Oral; Randomized Controlled Trials as Topic; Raynaud Disease [ ${ }^{\star}$ drug therapy]; Vasodilator Agents [ ${ }^{\star}$ administration \& dosage]

\section{MeSH check words}

Humans 